\title{
Asynchronous responses of East Asian and Indian summer monsoons to mountain uplift shown by regional climate modelling experiments
}

\author{
Hui Tang • Arne Micheels · Jussi T. Eronen • \\ Bodo Ahrens $\cdot$ Mikael Fortelius
}

Received: 2 January 2012/ Accepted: 12 November 2012/Published online: 5 December 2012

(C) The Author(s) 2012. This article is published with open access at Springerlink.com

\begin{abstract}
It has been demonstrated in climate models that both the Indian and East Asian summer monsoons (ISM and EASM) are strengthened by the uplift of the entire Asian orography or Tibetan Plateau (TP) (i.e. bulk mountain uplift). Such an effect is widely perceived as the major mechanism contributing to the evolution of Asian summer monsoons in the Neogene. However, geological evidence suggests more diachronous growth of the Asian orography (i.e. regional mountain uplift) than bulk mountain uplift. This demands a re-evaluation of the relation between mountain uplift and the Asian monsoon in the geological periods. In this study, sensitivity experiments considering the diachronous growth of different parts of the Asian orography are performed using the regional climate model COSMO-CLM to investigate their effects on the Asian summer monsoons. The results show that, different from
\end{abstract}

Electronic supplementary material The online version of this article (doi:10.1007/s00382-012-1603-x) contains supplementary material, which is available to authorized users.

H. Tang $(\bowtie) \cdot$ J. T. Eronen · M. Fortelius

Department of Geosciences and Geography, University

of Helsinki, P.O. Box 64, 00014 Helsinki, Finland

e-mail: hui.tang@helsinki.fi

A. Micheels $\cdot$ J. T. Eronen

Biodiversity and Climate Research Centre (LOEWE BiK-F),

Senckenberganlage 25, 60325 Frankfurt am Main, Germany

A. Micheels

Senckenberg Research Institute and Nature Museum,

Senckenberganlage 25, 60325 Frankfurt am Main, Germany

B. Ahrens

Institute for Atmospheric and Environmental Sciences, Goethe University, Altenhoeferallee 1, 60438 Frankfurt am Main, Germany the bulk mountain uplift, the regional mountain uplift can lead to an asynchronous development of the ISM and EASM. While the ISM is primarily intensified by the thermal insulation (mechanical blocking) effect of the southern TP (Zagros Mountains), the EASM is mainly enhanced by the surface sensible heating of the central, northern and eastern TP. Such elevated surface heating can induce a low-level cyclonic anomaly around the TP that reduces the ISM by suppressing the lower tropospheric monsoon vorticity, but promotes the EASM by strengthening the warm advection from the south of the TP that sustains the monsoon convection. Our findings provide new insights to the evolution of the Asian summer monsoons and their interaction with the tectonic changes in the Neogene.

Keywords Mountain uplift · East Asian summer monsoon (EASM) · Indian summer monsoon (ISM) · Regional climate model · Asynchronous evolution · Thermal effect

\section{Introduction}

The Tibetan Plateau (TP) and the surrounding orography, which peak above $8,000 \mathrm{~m}$, cover more than $70 \%$ of the land surface in Asia. Most of the Asian orography was built in the Cenozoic as a result of the continental collisions between India (or Arabia) and Eurasia (Yin 2010). The growth of these mountains, especially the TP, has had crucial impact on the formation and development of the Asian monsoon climate on geological time scale (An et al. 2001; Kutzbach et al. 1989; Liu and Yin 2002; Prell and Kutzbach 1992; Ramstein et al. 1997; Zhang et al. 2007). 
A prominent feature of the Asian monsoon climate is the warm, wet summer monsoon. It can be divided into the Indian and East Asian summer monsoon (EASM) systems, which share common features but also exhibit unique attributes. In general, the Indian summer monsoon (ISM) is embedded in tropical climate systems and the meridional Hadley circulation, while the EASM is more subject to the mid-latitude processes, such as westerly jet stream and frontal systems (Molnar et al. 2010). In spite of these differences, it has been demonstrated that both the ISM and EASM are strengthened by the increasing height of the entire TP or Asian orography (referred to as "bulk mountain uplift" hereafter) (e.g. An et al. 2001; Kutzbach et al. 1993; Song et al. 2010). In India, this is represented by the emergence and deepening of the monsoon trough over northern India, the enhancement of the low-level southwesterly flow over the Arabian Sea and India, and the northward migration of the Intertropical Convergence Zone (ITCZ) (Abe et al. 2003; An et al. 2001; Fluteau et al. 1999; Hahn and Manabe 1975). In East Asia, it is characterized by the intensification and northward penetration of the low-level southerly flow, the inland-ward expansion of the Western North Pacific (WNP) Subtropical High and the rain front along its northern periphery (e.g. An et al. 2001; Jiang et al. 2008; Kitoh 2004; Liu and Yin 2002). Such effects on the ISM and EASM have been largely attributed to the diabatic heating of the uplifted plateau which maintains an upper tropospheric thermal high pressure over the TP. This leads to a divergent flow in the upper troposphere and a low-level convergent flow around the plateau that brings precipitation to both Indian (Kutzbach et al. 1993; Li and Yanai 1996) and East Asian (Duan and Wu 2005; Duan et al. 2008; Wu et al. 2012) continent. The monsoonal precipitation can further enhance the upperlevel thermal high pressure over the TP by latent heat release, therefore amplify the thermal pumping effect of the TP (Yanai and Wu 2006).

The effects of bulk mountain uplift have been widely applied to interpreting the Asian monsoon evolution in the Neogene (since 23 Ma B. P.) (e.g. An et al. 2001; Wang et al. 2005). However, growing geological evidence challenged the "bulk uplift-monsoon" hypothesis (e.g. Molnar et al. 2010). On the one hand, the tectonic and palaeoaltimetry studies support more a diachronous growth of different parts of the TP and the surrounding mountains than a bulk mountain uplift (Harris 2006; Shen et al. 2001; Tapponnier et al. 2001; Yin 2010). It has been suggested that the southern and central TP may have attained its present-day height in the Middle Miocene (16-11 Ma) (Fig. 1b), while the major rise of the northeastern TP may have occurred late in the Late Miocene and Pliocene (8-3 Ma) (Fig. 1). On the other hand, palaeo-monsoon proxies have revealed an asynchronous inception and development of the ISM and EASM in several geological periods (e.g. Fortelius et al. 2002; Guo et al. 2008; Jiang and Ding 2008; Wang et al. 2005) (see more discussion in Sect. 5). Such asynchrony is incompatible with the bulk mountain uplift being the major control of monsoon evolution.

The influence of different parts of the Asian orography (referred to as "regional mountain uplift") on the summer monsoons has been tentatively investigated in some modeling studies. Chakraborty et al. (2002) find that the presence of the western $\mathrm{TP}$ is more instrumental to the formation of the ISM than its eastern part. Boos and Kuang (2010) further show that the presence of the narrow orography of the Himalayas and the adjacent mountain ranges is sufficient to sustain an ISM of present-day strength. They inferred that it is the orographic insulation of low entropy

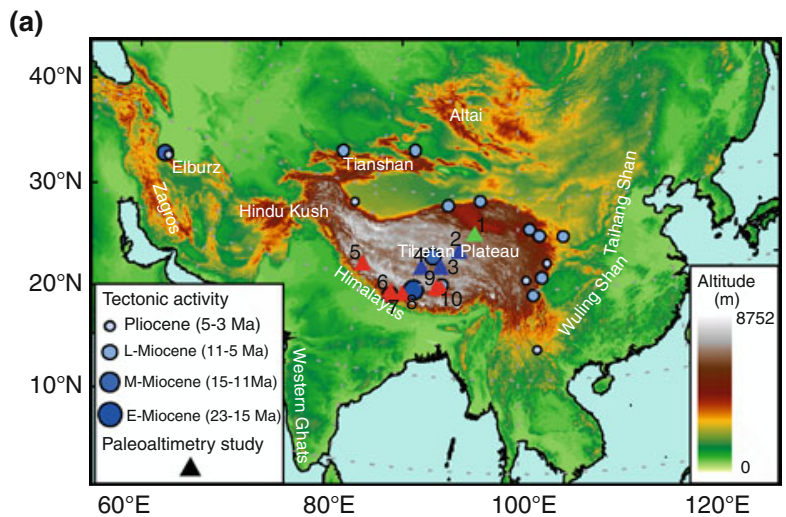

(b)

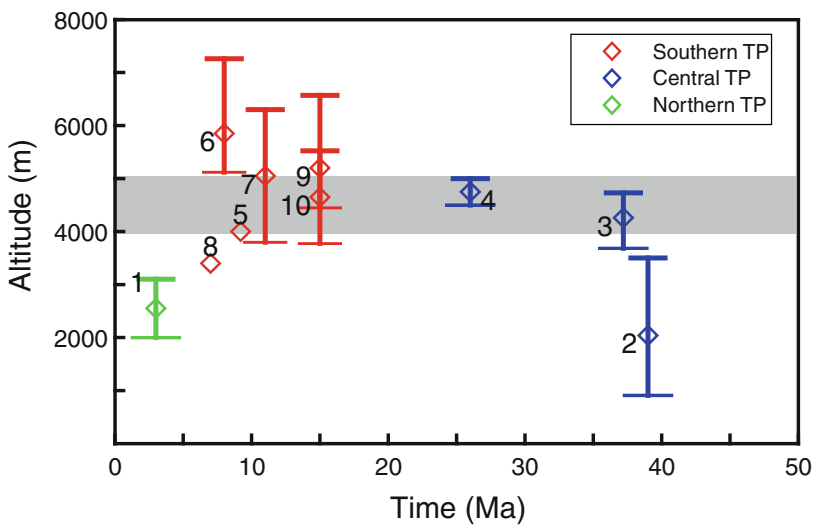

Fig. 1 Tectonic history of Asian orography in Neogene. a locations of tectonic (circle) and palaeo-altitude (triangle) studies that imply mountain building (see references in Online Resource 1). b palaeoaltitude of the Tibetan Plateau. The number of each point in (b) corresponds to the number of each location shown in (a). 1 . Kunlun Pass (Wang et al. 2008b); 2. Fenghuo Shan (Cyr et al. 2005); 3. Lunpola Basin (Rowley and Currie 2006); 4. Nima Basin (DeCelles et al. 2007); 5. Zhada Basin (Saylor et al. 2009); 6. Thakkhola Graben (Rowley et al. 2001); 7. Thakkhola Graben (Garzione et al. 2000); 8. Gyirong Basin (Wang et al. 2006); 9. Namling Basin (Currie et al. 2005); 10. Namling Basin (Spicer et al. 2003). The gray bar denotes the present-day averaging height of the Tibetan Plateau 
extratropical air mass by the narrow mountain chains (i.e. "thermal insulation") rather than the diabatic heating of the entire elevated plateau which maintains the ISM. They also noticed that the present-day EASM does not emerge with only the presence of such narrow mountain chains. This leads the authors to the contention that the formation of the EASM must be tied to the meridional extent of the TP and its mechanical impact on the westerly jet stream (Boos and Kuang 2010; Molnar et al. 2010). This idea, however, has recently been challenged by $\mathrm{Wu}$ et al. (2012), who emphasize the importance of the elevated heating of different regional mountains in driving either the ISM or the EASM

So far, the more specific effects of the regional mountain uplift on both the ISM and EASM in different geological periods remain elusive. Most studies rely on global climate models, which, hampered by their coarse spatial resolution, cannot sufficiently capture the influence of a regional-scale mountain uplift. Compared to global models, regional climate models allow higher spatial resolutions and more detailed description of small-scale dynamical and physical processes, therefore, provide valuable tools in identifying the influence of meso-scale orographic features on the Asian summer monsoon climate (Chow et al. 2006; Gao et al. 2006; Park and Hong 2004; Shi et al. 2008; Song et al. 2010; Xie et al. 2006). In this study, a regional climate model-COSMO-CLM driven by the output of the fullycoupled atmosphere-ocean general circulation model (AOGCM) COSMOS - is employed to further explore the impact of regional mountain growth on the Asian summer monsoons. The model configuration and experimental design are described in Sect. 2. In Sect. 3, we show that distinct from the effect of bulk mountain uplift, the regional mountain uplift triggers asynchronous changes between ISM and EASM. The mechanisms for such asynchronous summer monsoon response are examined in Sect. 4. Finally, the implication of our results to the evolution of the Asian monsoon in the Neogene is discussed in Sect. 5.

\section{Methods}

\subsection{The COSMO-CLM model and model setup}

The COSMO-CLM is the climate mode of a non-hydrostatic regional weather prediction model COSMO (Consortium for Small-scale Modelling) (available at http://www.clm-community.eu). It can simulate the modern Asian monsoon circulation and precipitation well compared to other regional climate models (Dobler and Ahrens 2010; Lucas-Picher et al. 2011; Rockel and Geyer 2008) and has been applied to projecting the Asian summer monsoon changes into the future (Dobler and Ahrens
2011). The model uses a rotated geographical coordinate system. Its vertical domain is represented by a terrainfollowing hybrid coordinate system ( $\eta$ coordinate). Consistent with our previous regional model study on the Asian climate in the Late Miocene (11-7 Ma) (Tang et al. 2011), we adopted the model version 2.4 .11 and chose the leapfrog numerics, the Tiedtke convection scheme (Tiedtke 1989), the radiation transfer scheme based on Ritter and Geleyn (1992), the prognostic turbulent kinetic energy closure (TKE) (Raschendorfer 2001) and the TERRA-ML multi-layer soil-vegetation-atmosphere-transfer model (Schrodin and Heise 2002) for all the experiments in this study. The model domain covers the Asian monsoon area $\left(0-60^{\circ} \mathrm{N}\right.$ and $\left.50-140^{\circ} \mathrm{E}\right)$ with a spatial resolution of $1^{\circ} \times 1^{\circ}$ on the rotated model grid (the north pole is at $\left.60^{\circ} \mathrm{N}, 80^{\circ} \mathrm{W}\right)$ and 20 vertical levels.

\subsection{Experiment design}

To study the climatic effects of regional mountain uplift, six sensitivity experiments were carried out in our regional model (Table 1). In the first experiment, all the present-day orography higher than $250 \mathrm{~m}$ is removed (the orography lower than $250 \mathrm{~m}$ is kept), which is referred to as M00 (Fig. 2a). Then, the present-day southern TP, central TP and northeastern-southeastern TP (referred to as "northern TP" in short hereafter) are added successively, which are referred to as MsTibet, McTibet and MnTibet, respectively (Fig. 2b-d). In the experiment MZagros, the present-day height of the complex mountain chains, including the Zagros to the south and the Elburz to the north in Iran, and the Hindu Kush in Afghanistan and Pakistan (referred to as "Zagros Mountains" in short hereafter) are present (Fig. 2e). In the experiment MTian, the present-day Tianshan and Gobi Altai Mountains to the north of the TP are further added (Fig. 2f). The control run with all the present-day orography is referred to as M100 (Fig. 2h). Since the palaeo-altitude of the Asian orography is still poorly

Table 1 Summary of the model experiments

\begin{tabular}{ll}
\hline Experiments & Orographic configuration \\
\hline M00 & No mountains ( $\leq 250 \mathrm{~m}$ above sea level) \\
MsTibet & $\begin{array}{l}\text { The southern TP is added compared to M00 } \\
\text { McTibet }\end{array}$ \\
The central TP is added compared to MsTibet \\
MnTibet & $\begin{array}{r}\text { The northern and southeastern TP are added compared } \\
\text { to McTibet } \\
\text { MZagros }\end{array}$ \\
The Zagros and Hindu Kush Mountains are added \\
compared to MnTibet \\
MTian & $\begin{array}{r}\text { The Tianshan and Gobi Altai Mountains are added } \\
\text { compared to MZagros }\end{array}$ \\
M50 & $\begin{array}{l}50 \% \text { of the present-day height of all the orography } \\
\text { M100 }\end{array}$
\end{tabular}




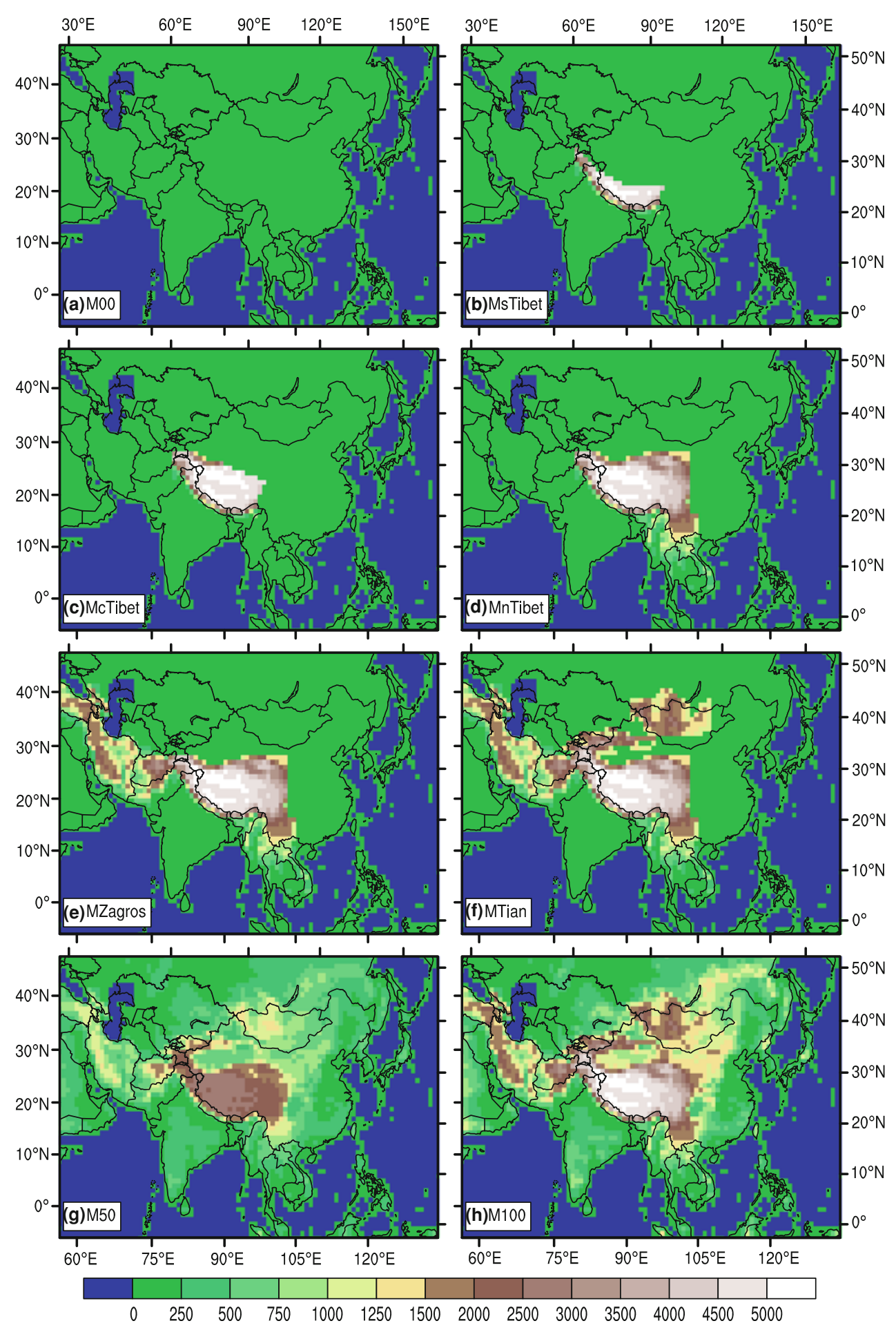

Fig. 2 Surface elevation for bulk and regional mountain uplift experiments. a M00, b MsTibet, c McTibet, d MnTibet, e MZagros, f MTian, g M50, h M100

quantified, our regional mountain uplift experiments intend not to exactly follow, but to generally mimic its growth in geological periods (Fig. 1). More discussion on the rationale of our experimental design can be found in Online Resource 2. In order to compare the effect of regional mountain uplift with that of bulk mountain uplift, an experiment with all the orography $(>250 \mathrm{~m})$ reduced to $50 \%$ of its present-day height was also performed (referred to as M50) (Fig. 2g). In all these experiments, only the surface elevation is modified. Other physical boundary conditions, such as land-sea distribution, vegetation and $\mathrm{CO}_{2}$ concentration $(360 \mathrm{ppm})$, are the same as at present. 
Our regional model experiments are driven by 6-hourly output from both a present-day control run and a Late Miocene run performed in the AOGCM COSMOS (Eronen et al. 2009; Micheels et al. 2011). Compared to the presentday global control run, the Late Miocene run has lower orography globally. It represents a global climate generally warmer and wetter than at present and exhibits stronger mid-latitude westerlies throughout a year (Micheels et al. 2011). Particularly in Asia, the whole TP is reduced to about $70 \%$ of its present-day height. Both the Indian and East Asian summer monsoon circulation is weaker than in the present-day run (Tang et al. 2011). However, summer precipitation in India is stronger in the Late Miocene run because of the high sea surface temperature over the Indian Ocean (Micheels et al. 2011). We expect that such difference in global forcings may affect the climatic response to mountain uplift in our regional model. However, such influence turns out to be small. Therefore, only the outcome driven by the Late Miocene global run is presented in this paper. The results under the present-day global forcing are briefly analyzed in Online Resource 3.

All the regional model experiments are integrated for 10 years. Because the initial adaptation of the upper-level soil moisture takes only a few months (Tang et al. 2011), the first year integration is left for the model to spin up, and the last 9-year results are used for analysis.

\section{Effects of mountain uplift on summer monsoon}

\subsection{Bulk mountain uplift}

Present-day Asian summer monsoon climate is characterized by strong low-level westerly wind over the Arabian Sea and India (i.e. the ISM wind), and southerly wind over East Asia (i.e. the EASM wind), which bring abundant rainfall far into the continent (Fig. 3b). The removal of all the Asian orography greatly suppresses such summer monsoon flows and precipitation (cf. Fig. 3a, b). It is shown that the bulk mountain uplift from 0 to $50 \%$ of the present-day height (i.e. M50 - M00) enhances the low-level monsoon wind in both India and E-China. This is accompanied by an increase of summer precipitation in India, the southern $\mathrm{TP}$ and E-China (Fig. 3c). The bulk mountain uplift from 50 to $100 \%$ of the present-day height (M100 - M50) results in a similar
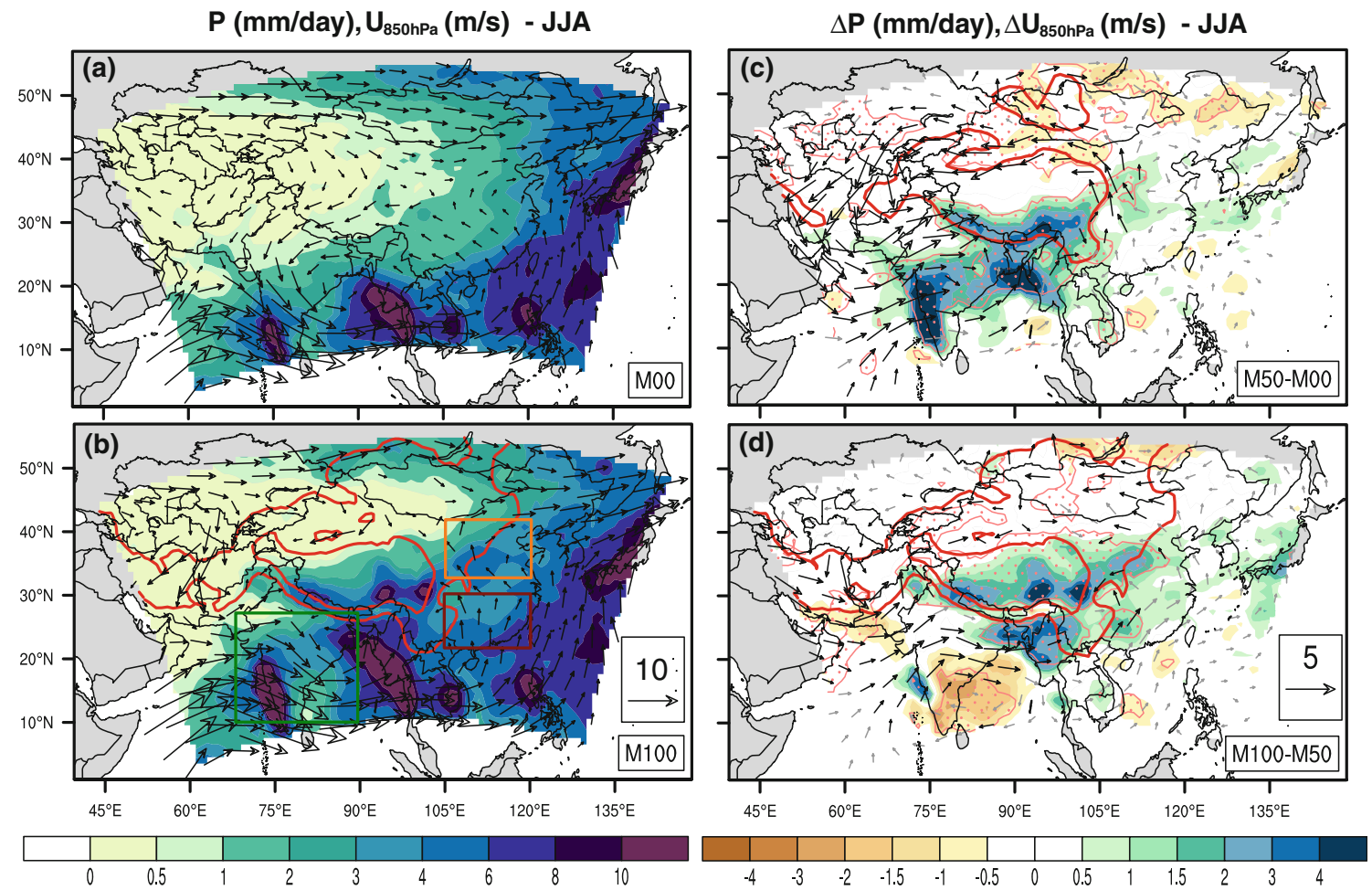

Fig. 3 Summer (JJA) precipitation $\left(\mathrm{mm} \mathrm{day}^{-1}\right)$ and $850 \mathrm{hPa}$ wind $\left(\mathrm{m} \mathrm{s}^{-1}\right)$ changes with bulk mountain uplift. a M00, b M100, c M50 minus M00, $\mathbf{d}$ M100 minus M50. The red contours surround the areas with surface pressure lower than 900 and $700 \mathrm{hPa}$. The rectangles in b denote the regions for precipitation averaging in Fig. 5. Northern China (N-China: $105-120^{\circ} \mathrm{E}, 34-42^{\circ} \mathrm{N}$, orange), southern China (S-China: $105-120^{\circ} \mathrm{E}, 22-30^{\circ} \mathrm{N}$, brown), India $\left(70-90^{\circ} \mathrm{E}, 10-28^{\circ} \mathrm{N}\right.$,

green). S-China and N-China together are referred to as E-China in the text. In $\mathbf{c}$ and $\mathbf{d}$, the region dotted with coral colour denotes precipitation anomalies significant with a Student's $t$ test $(p<0.1)$. The black vectors indicate that either the zonal or meridional wind differences are significant with a Student's $t$ test $(p<0.1)$. Note that the sponge layer of the regional model domain (i.e. the outermost 8 grid cells) has been removed in the figure 
but slightly different changes (Fig. 3d). In India, the lowlevel southwesterly wind and precipitation is further strengthened in its northern part, but is weakened in the south. This indicates a northward shift of the monsoonal convergence and the associated precipitation rather than a broad enhancement of the ISM as in the previous stage of bulk mountain uplift. In East Asia, the strengthening of the low-level southerly wind and precipitation, however, is more extensive than in the previous stage of bulk mountain uplift (Fig. 3d). Generally, these results agree well with previous model studies (An et al. 2001; Kitoh 2004; Kutzbach et al. 1993; Song et al. 2010), demonstrating a synchronous intensification of the ISM and EASM with bulk mountain uplift.

\subsection{Regional mountain uplift}

\subsubsection{Precipitation and $850 \mathrm{hPa}$ wind}

Compared to bulk mountain uplift, regional mountain uplift displays distinct impact on the Asian summer monsoons (Fig. 4). The presence of the southern TP (i.e. MsTibet M00) and the Zagros Mountains (i.e. MZagros - MnTibet) greatly enhance the ISM wind and precipitation, but reduce the EASM wind and precipitation in general (Fig. 4a, d). On the contrary, the presence of the central TP (i.e. McTibet MsTibet), northern TP (i.e. MnTibet - McTibet) and the Tianshan-Altai Mountains (i.e. MTian - MZagros) strongly promotes the summer precipitation and low-level

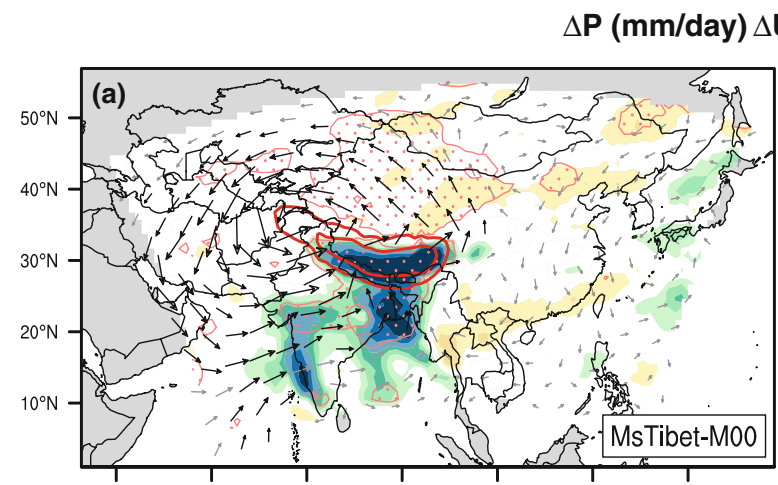

$\Delta \mathbf{U}_{850 \mathrm{hPa}}(\mathrm{m} / \mathrm{s})$ - JJA
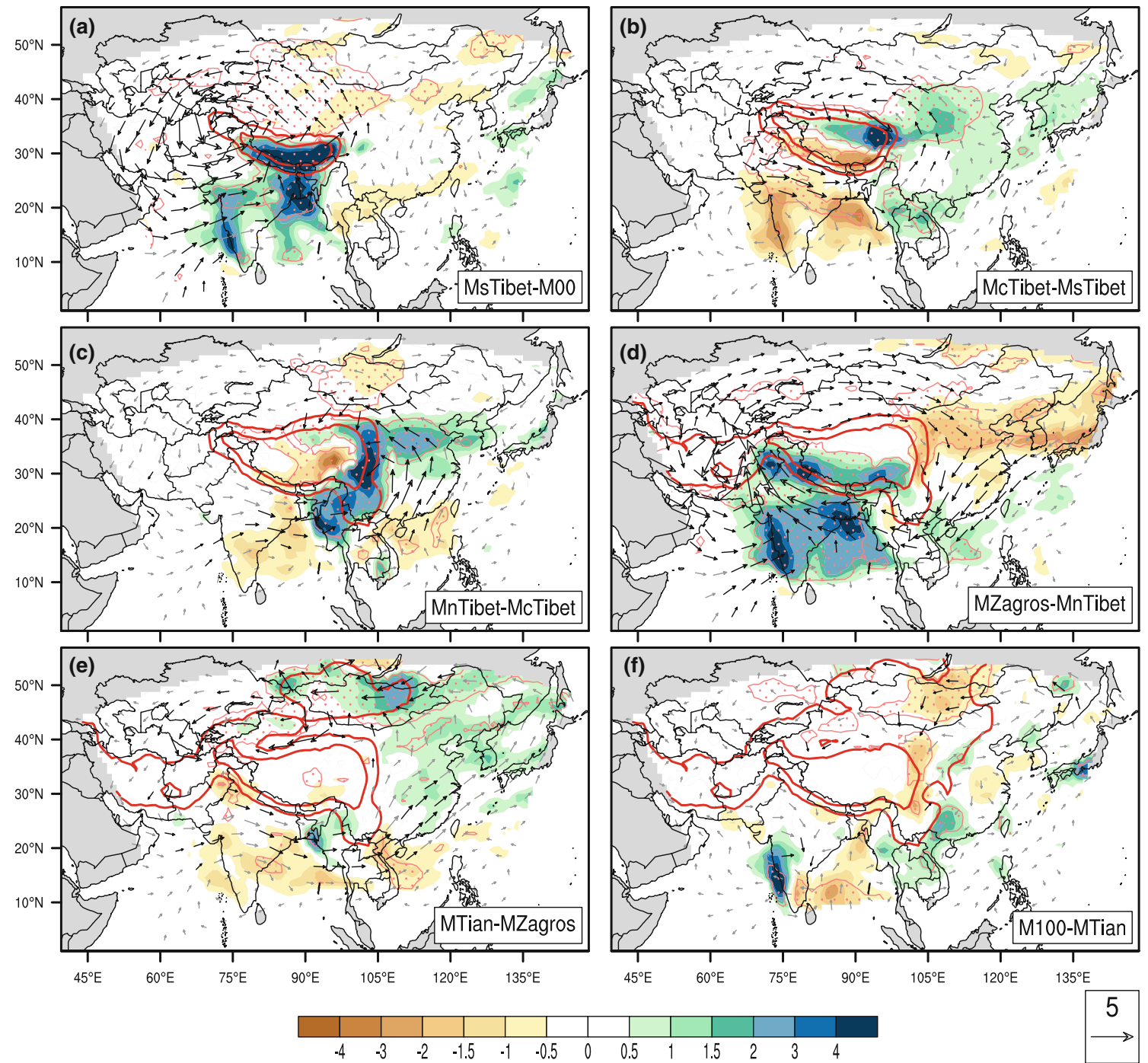

Fig. 4 As in Fig. 3, but for regional mountain uplift. a MsTibet minus M00, b McTibet minus MsTibet, c MnTibet minus McTibet, d MZagros minus MnTibet, e MTian minus MZagros, f M100 minus MTian 
southerly wind in East Asia, but results in an anticyclonic wind anomaly over India that suppresses the summer precipitation there (Fig. 4b, c, e). These results indicate an asynchronous development of the ISM and EASM in response to the regional mountain uplift. The presence of other secondary orography (i.e. M100 - MTian) has little influence on large-scale monsoon circulation, but redistributes monsoon rainfall on a regional scale (Fig. 4f). For instance, an increase (decrease) of precipitation over the western (eastern) coast of India and eastern (western) Loess Plateau is evident, probably due to the presence of the Western Ghats in India (Gunnell 1997) and the Taihang Mountains in China.

The monthly evolution of precipitation over the major monsoon regions, i.e. N-China, S-China and India, in all the experiments are illustrated in Fig. 5. It shows that in S-China, the changes of precipitation due to mountain uplift mainly occur in spring and early summer (from March to June) (Fig. 5b). This is consistent with Park et al. (2012) who showed a preferred increase of precipitation in the downstream region of the uplifted TP in spring and early summer. In contrast, the changes of precipitation occur in the entire summer monsoon season (from May to September) over India, and even in a longer period over N-China (From April to September). Nevertheless, the most pronounced changes in precipitation due to mountain uplift are seen in early summer (i.e. June) in all the three regions. It is noted that the present-day orography (i.e. M100) does not necessarily correspond to the highest rainfall in the monsoon regions, such as $\mathrm{N}$-China, where the highest rainfall is observed when only the TP (i.e. MnTibet) is present.

The development of the low pressure centre at sea level over northern India (i.e. the Indian monsoon trough) plays a vital role in forming the summer rainfall over India (Hahn and Manabe 1975). Particularly, the deepening and focusing of the low pressure centre to northwestern India in mid and late summer, which draws the southeasterly flow from the Bay of Bengal to northern India, can greatly facilitate moisture convergence and rainfall over the northern Indian subcontinent (Bollasina and Nigam 2010). As illustrated in Fig. 6, the regional mountain uplift gradually deepens the low pressure centre over northern India. However, while the presence of the southern TP and the Zagros Mountains displaces it northwest-ward (Fig. 6b, e), the presence of the other mountain regions favors its growth toward the east (Fig. 6c, d, f), which, in fact, suppresses the southeasterly flow from the Bay of Bengal to northern India and the summer rainfall there (Fig. $4 \mathrm{~b}, \mathrm{c}, \mathrm{e}$ ). It is noticed that the southwesterly monsoon wind and the pronounced increase of summer rainfall over western India and Pakistan only emerge when the Hindu Kush and Zagros Mountains are present (Figs. 4d, 6e).
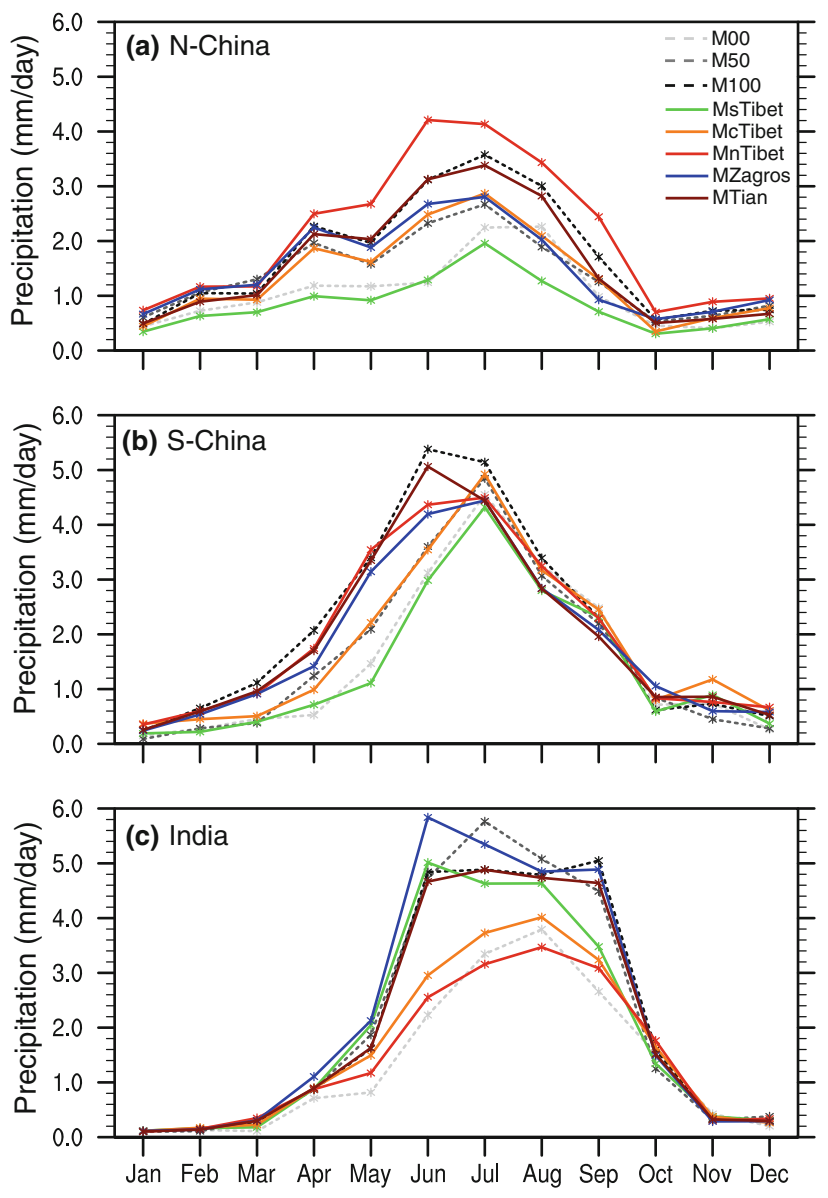

Fig. 5 Monthly mean precipitation $\left(\mathrm{mm} \mathrm{day}^{-1}\right)$ change over N-China (a), S-China (b) and India (c) (as denoted in Fig. 3b)

\subsubsection{Monsoon indices}

To further elucidate the changes in summer monsoon intensity due to mountain uplift, several summer monsoon indices are calculated (Fig. 7). WY is defined as JJA-mean zonal wind difference between 850 and $200 \mathrm{hPa}$ over South Asia $\left(60-110^{\circ} \mathrm{E}, 5-20^{\circ} \mathrm{N}\right)$ (based on Webster et al. 1998). MH is defined by JJA-mean meridional wind difference between 850 and $200 \mathrm{hPa}$ over the ISM region $\left(70-110^{\circ} \mathrm{E}\right.$, $10-30^{\circ} \mathrm{N}$ ) (based on Goswami et al. 1999). IMI is JJAmean zonal wind difference at $850 \mathrm{hPa}$ between southern India $\left(60-80^{\circ} \mathrm{E}, 5-15^{\circ} \mathrm{N}\right)$ and northern India $\left(70-90^{\circ} \mathrm{E}\right.$ and $20-30^{\circ} \mathrm{N}$ ) (based on Wang et al. 2001). These indices capture different dynamical aspects of the ISM, such as the traverse monsoon circulation (WY), monsoon Hadley circulation (i.e. meridional overturning) $(\mathrm{MH})$ and lower tropospheric vorticity associated with the Indian monsoon trough (IMI). The EASM intensity is characterized by two low-level southerly wind indices (SWI and SWII). SWI is defined by $850 \mathrm{hPa}$ meridional wind velocity in E-China $\left(110-125^{\circ} \mathrm{E}, 20-40^{\circ} \mathrm{N}\right)(\mathrm{JJA}-\mathrm{mean})$ [adapted from $\mathrm{I}_{\mathrm{WN}}$ in 
Fig. 6 Summer sea level pressure (hPa, contour) and $850 \mathrm{hPa}$ wind $\left(\mathrm{m} \mathrm{s}^{-1}\right.$, vector) over India. a M00, b MsTibet, c McTibet, d MnTibet, e MZagros, $f$ MTian. The $996 \mathrm{hPa}$ contour is highlighted by red colour. The colour of vectors denotes horizontal relative vorticity $\left(10^{-6} \mathrm{~s}^{-1}\right)$ (red = negative;

blue $=$ positive). The area which surface pressure is lower than $850 \mathrm{hPa}$ is shaded by white colour

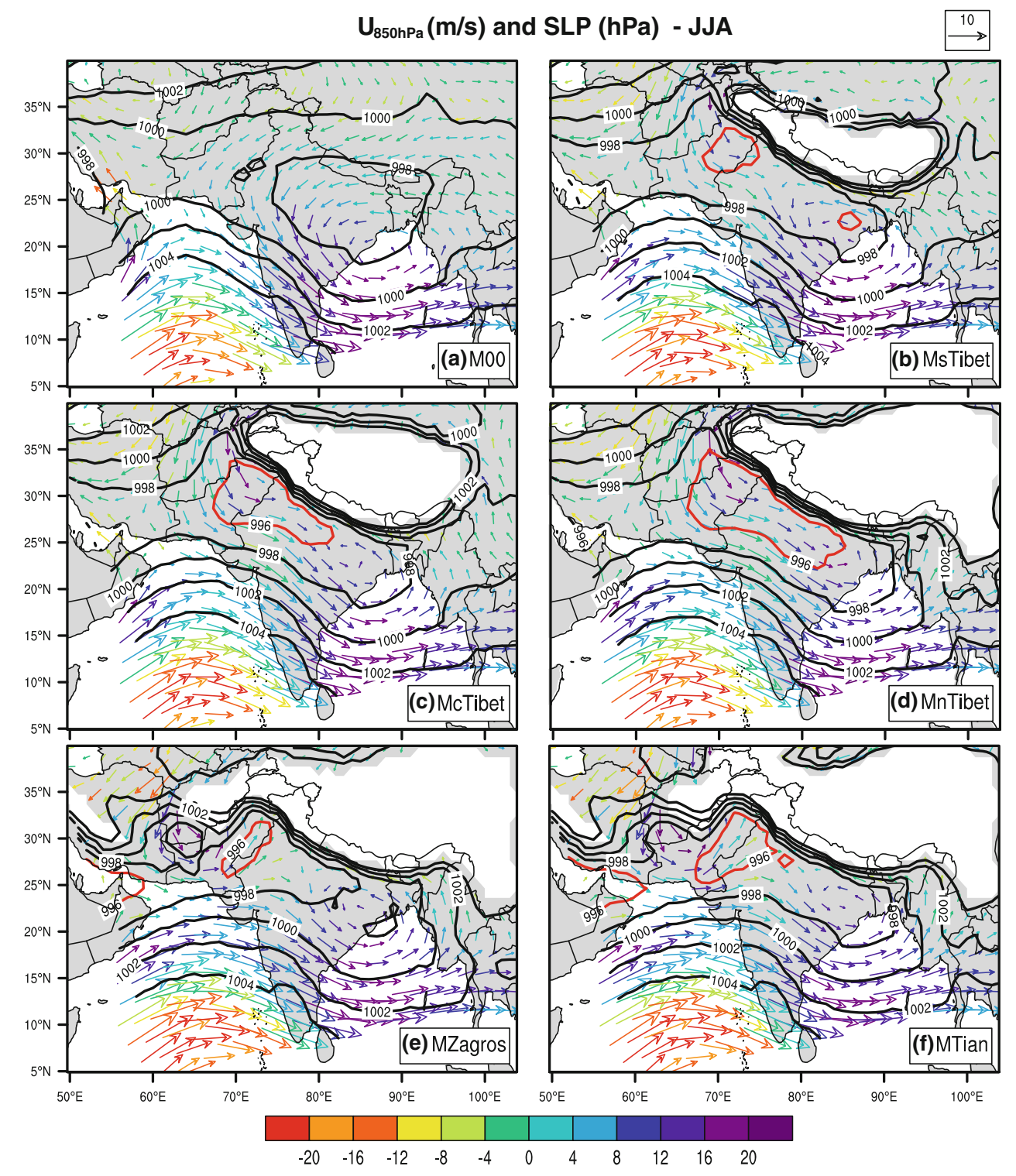

Wang et al. (2008a)]. SWII is defined by $850 \mathrm{hPa}$ meridional wind difference between southern $\left(110-125^{\circ} \mathrm{E}\right.$, $\left.20-30^{\circ} \mathrm{N}\right)$ and northern $\left(110-125^{\circ} \mathrm{E}, 30-40^{\circ} \mathrm{N}\right)$ China [adapted from $\mathrm{I}_{\mathrm{WwO}}$ in Wang et al. (2008a)]. While SWI depicts the general intensity of northward moisture transport, SWII reflects the intensity and position of moisture convergence in East Asia. They both are closely related to the major mode of the modern EASM variability, and have been commonly applied to depicting the palaeo-monsoon strength in East Asia (Wang et al. 2008a).

It exhibits that except IMI, all the monsoon indices increase with bulk mountain uplift (Fig. 7a), indicating a synchronous strengthening of the ISM and EASM. The ISM and EASM indices respond differently to regional mountain uplift, however (Fig. 7b). The ISM indices mainly increase when the southern TP and the Zagros
Mountains are uplifted. In contrast, the major rise of the EASM indices occurs when the northern TP are present. Among the ISM indices, WY and MH are closely related to each other $(r=0.98, p<0.0001)$ (Fig. 7). The low-level circulation index (IMI), is decoupled to WY $(r=0.24)$ and MH $(r=0.49)$, but is most associated with precipitation in India (Table 2), indicating a strong control of IMI on the response of the ISM to mountain uplift. The two EASM indices (SWI and SWII) change consistently with mountain uplift ( $r=0.79, p<0.02)$, and both are positively correlated with summer precipitation over E-China (Table 2). The in-phase changes between SWI and SWII (Fig. 7) suggest a general strengthening (or weakening) of the summer monsoon with mountain uplift over entire E-China. This is in contrast to the anti-phase change between SWI and SWII in our previous study (Tang et al. 
(a)

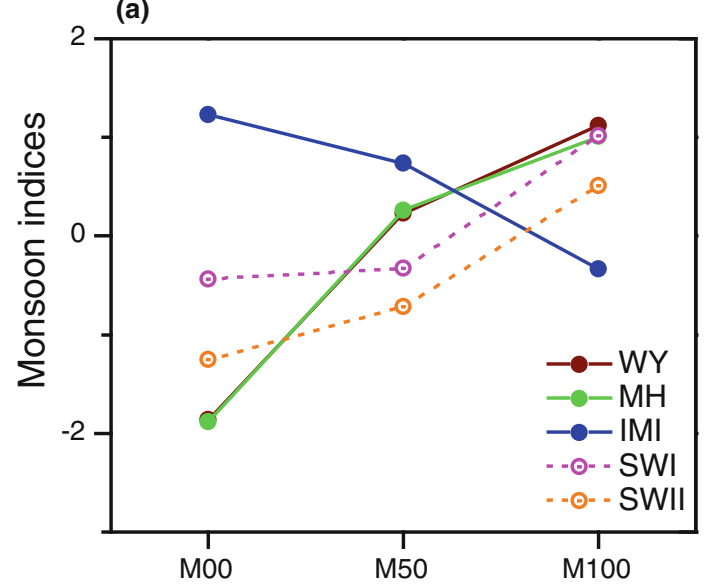

(b)

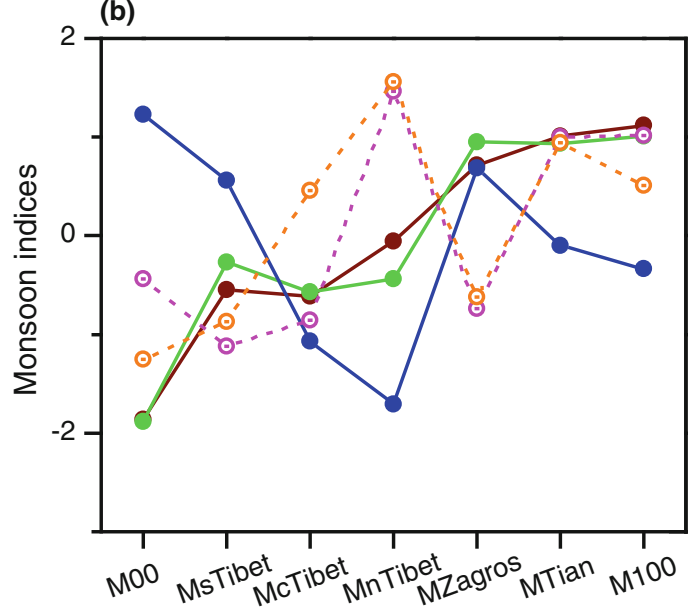

Fig. 7 Changes of summer monsoon indices with bulk and regional mountain uplift. All the monsoon indices have been standardized for better visualization

Table 2 Correlation coefficients of the ISM and EASM indices (same as in Fig. 7) with precipitation in India, N-China and S-China in all the mountain uplift experiments

\begin{tabular}{lcccrr}
\hline & WY & MH & IMI $^{\mathrm{a}}$ & \multicolumn{1}{c}{ SWI } & SWII \\
\hline Precipitation $_{\text {India }}{ }^{\mathrm{b}}$ & 0.68 & $\mathbf{0 . 7 8}$ & $\mathbf{0 . 9 5}$ & -0.20 & -0.27 \\
Precipitation $_{\text {N-China }}{ }^{\mathrm{b}}$ & 0.56 & 0.41 & -0.72 & $\mathbf{0 . 8 9}$ & $\mathbf{0 . 9 1}$ \\
Precipitation $_{\text {S-China }} \mathrm{b}$ & 0.68 & 0.58 & -0.37 & $\mathbf{0 . 7 6}$ & 0.60 \\
\hline
\end{tabular}

The numbers in bold are significant at 0.05 level

a The calculation of all the correlation coefficients with IMI does not include the values from M00. IMI shows the highest value in M00 (Fig. 7). This has nothing to do with the monsoon vorticity caused by the monsoon trough, but a reflection of the difference between planetary southwesterly (northeasterly) wind south (north) of the tropical convergence zone (Fig. 6a)

b JJA mean precipitation over India, N-China and S-China. The regions for India, N-China and S-China are the same as in Fig. 5

2011) which corresponds to an increase (decrease) of precipitation in S-China (N-China) and a shift of the prevailing monsoon system.

\section{Mechanisms for asynchronous summer monsoon response}

\subsection{Thermal effect: elevated heating versus thermal insulation}

To evaluate the thermal effect of uplifted mountains on summer monsoon development, the changes of temperature averaged between 500 and $200 \mathrm{hPa}$ are shown in Fig. 8. In M00, the maximum free tropospheric temperature is located in the northern Indochina subcontinent and southern China around $20^{\circ} \mathrm{N}$ (Fig. 8a). The presence of the whole Asian orography extends the thermal maximum northwestward to northern Indian and the south of the Tibet (Fig. 8b). This gives rise to the upper-level anticyclonic flow south of the TP that promotes the low-level convergent flow over India (Fig. 3b). It displays that the presence of the southern TP is mainly responsible for the extension of the upper level thermal maximum to northern India (Fig. 8c). In contrast, the presence of the central and northern TP increases upper level temperature primarily over the plateau and to the east of it (Fig. 8d, e), while the presence of the Zagros Mountains slightly raises the temperature over India and largely reduces the upper level temperature to the northeast of the TP (Fig. 8f).

Our results are concordant with Boos and Kuang (2010), supporting the importance of the narrow mountains of the southern TP and the Zagros Mountains in maintaining the upper tropospheric thermal maximum to the south of the plateau and therefore, driving the ISM. However, whether this largely arises from the "thermal insulation" (Boos and Kuang 2010) or "diabatic heating" (Wu et al. 2012) of the southern TP and the Zagros Mountains remains ambiguous. It is also unclear how much the diabatic heating of the uplifted mountains contributes to the EASM development. To answer these questions, a set of sensitivity experiments were performed to assess the surface heating effect of the uplifted mountains. In these experiments, the model setup is the same as in the previous mountain uplift experiments (Table 1), except that the soil type and vegetation of the uplifted regions were modified to increase their surface albedo. This greatly reduces the surface heat flux of the uplifted regions to the atmosphere, particularly the sensible heat flux (Table 3 and Fig. S7 in Online Resource 4). We refer to these experiments as the No-Heating experiments. The differences between the No-Heating experiments and the corresponding mountain uplift experiments are illustrated in Fig. 9, which reflect the sensitivity of the Asian summer monsoons to the surface heating of different regional mountains in our model.

It shows that the enhanced heating over the southern TP can induce a cyclonic wind anomaly around the southern TP (Fig. 9a) and a great increase of precipitation over the 


\section{$\mathrm{T}_{200-500 \mathrm{hPa}}\left({ }^{\circ} \mathrm{C}\right), \mathrm{U}_{200 \mathrm{PPa}}(\mathrm{m} / \mathrm{s})-\mathrm{JJA}$}
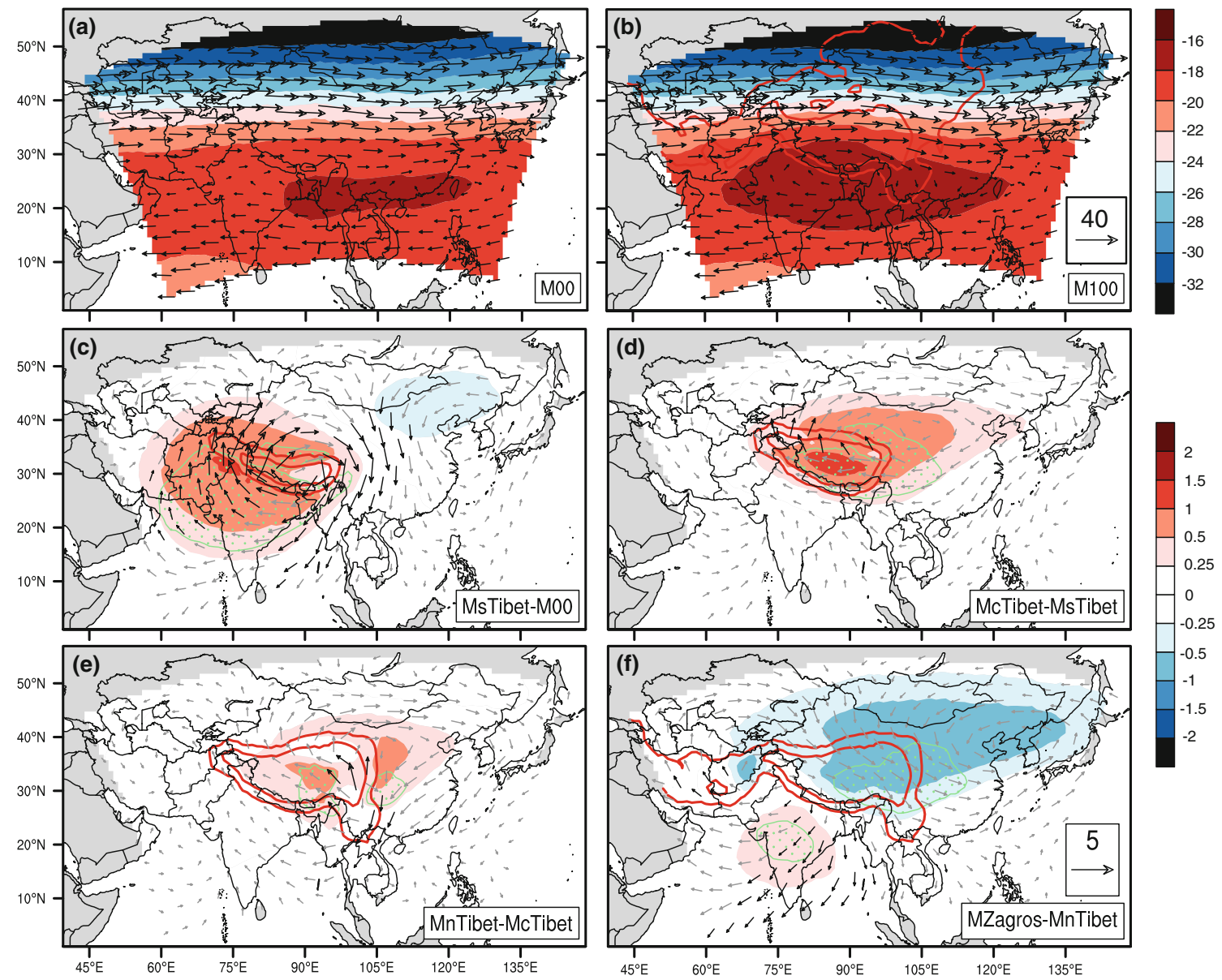

Fig. 8 Upper-level temperature $\left(\mathrm{T}_{200-500}\right)$ and $200 \mathrm{hPa}$ wind in summer and their changes with regional mountain uplift. a M00, b M100, c MsTibet minus M00, d McTibet minus MsTibet, e MnTibet minus McTibet, f MZagros minus MnTibet. The red contours surround the areas with surface pressure lower than 900 and $700 \mathrm{hPa}$. The doted region in (c-f) denotes temperature anomalies

significant with a Student's $t$ test $(p<0.1)$. The zonal or meridional wind differences significant with a Student's $t$ test $(p<0.1)$ are in black color. Since the presence of the Tianshan-Altai Mountains and other orography has negligible influence on the upper-level temperature and circulation, their figures are not shown

Table 3 The summer mean surface albedo and energy flux $\left(\mathrm{W} \mathrm{m}^{-2}\right)$ over the uplifted regions

\begin{tabular}{|c|c|c|c|c|c|c|c|c|}
\hline \multirow[t]{2}{*}{ Experiments } & \multicolumn{2}{|c|}{ Southern TP } & \multicolumn{2}{|c|}{ Central TP } & \multicolumn{2}{|c|}{ Northern TP } & \multicolumn{2}{|l|}{ Zagros } \\
\hline & MsTibet & MsTibetNoH & McTibet & McTibetNoH & MnTibet & MnTibetNoH & MZagros & MZagrosNoH \\
\hline Albedo & 0.18 & 0.7 & 0.18 & 0.7 & 0.16 & 0.7 & 0.18 & 0.7 \\
\hline Sensible heat flux & -39.74 & 12.59 & -68.11 & 16.44 & -46.29 & 13.17 & -88.58 & 44.47 \\
\hline Latent heat flux & -52.41 & -40.97 & -34.56 & -41.25 & -59.56 & -46.22 & -19.69 & $-66.79^{\mathrm{a}}$ \\
\hline Longwave radiation & -61.70 & -57.59 & -89.83 & -78.72 & -60.82 & -56.35 & -127.10 & -87.59 \\
\hline Total & -153.85 & -85.97 & -192.50 & -103.53 & -166.67 & -89.40 & -235.37 & -109.91 \\
\hline
\end{tabular}

The negative values of surface energy flux denote the energy flow from surface to the atmosphere, and vice versa. MsTibetNoH: same as MsTibet except that the present-day soil and vegetation over the southern TP are replaced by ice. McTibetNoH: same as McTibet except that the presentday soil and vegetation over the central TP are replaced by ice. MnTibetNoH: same as MnTibet except that the present-day soil and vegetation over the northern TP are replaced by ice. MZagrosNoH: same as MZagros except that the present-day soil and vegetation over the Zagros Mountains are replaced by ice

${ }^{a}$ The excessive increase of latent heat flux from the surface of the Zagros Mountains in MZagrosNoH compared to MZagros is due to the strong evaporation over ice with relatively high surface temperature. Such evaporative cooling in turn reduces the surface temperature, resulting in a large drop of the sensible heat flux and longwave radiation from the surface of the Zagros Mountains in MZagrosNoH 
$\Delta \mathrm{P}(\mathrm{mm} / \mathrm{day}), \Delta \mathbf{U}_{850 \mathrm{hPa}}(\mathrm{m} / \mathrm{s})$ - JJA
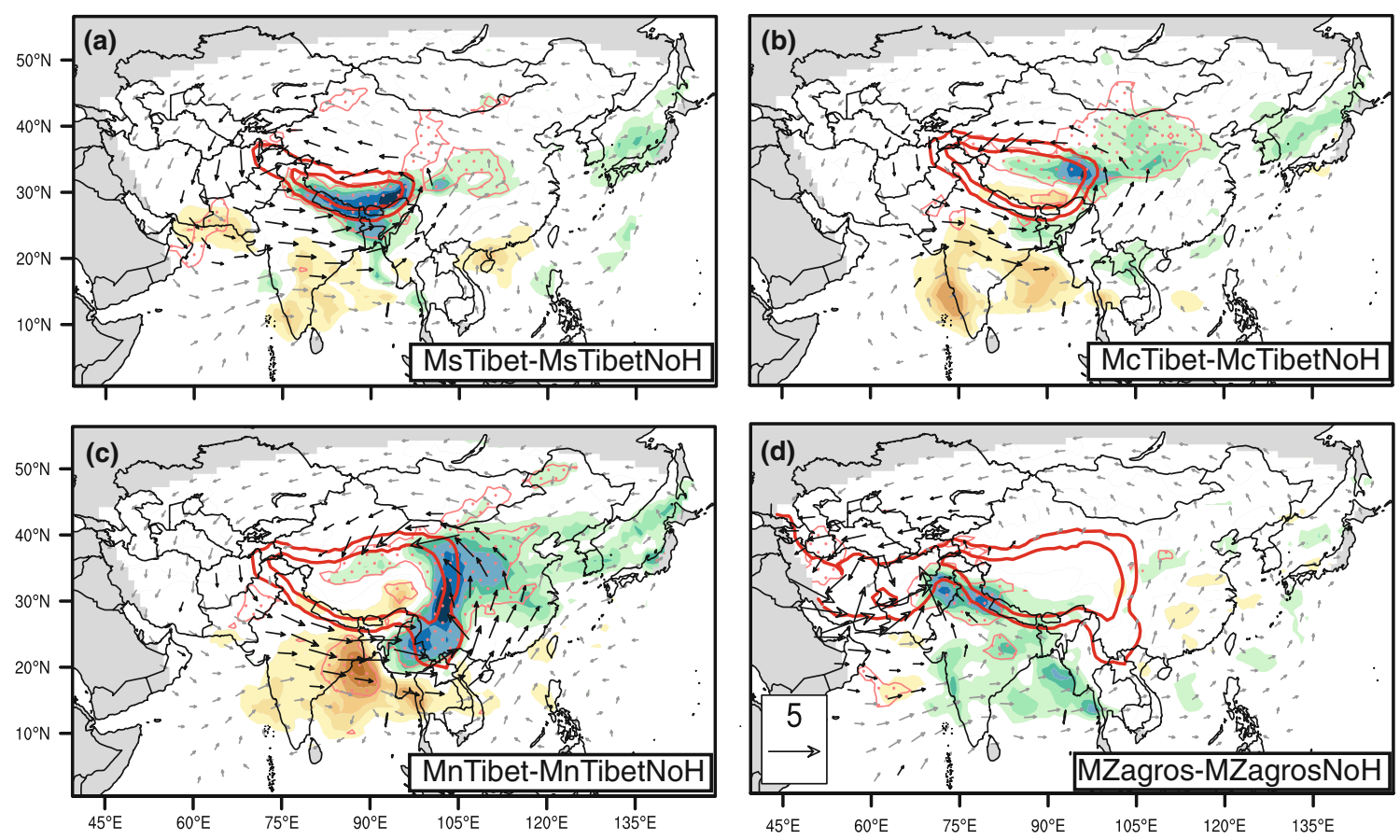

\begin{tabular}{l|l|l|l|l|l|l|}
\hline & & & & & & \\
\hline-4 & -3 & -2 & -1.5 & -1 & -0.5
\end{tabular}

Fig. 9 Summer precipitation $\left(\mathrm{mm} \mathrm{day}^{-1}\right)$ and $850 \mathrm{hPa}$ wind $\left(\mathrm{m} \mathrm{s}^{-1}\right)$ changes due to surface heating of the uplifted mountains. a MsTibet minus MsTibetNoH, b McTibet minus McTibetNoH, c MnTibet minus MnTibetNoH, d MZagros minus MZagrosNoH. The red contours surround the areas with surface pressure lower than 900 and

southern TP. There is also a slight increase of precipitation over East Asia, but little change (or even slight suppression) of precipitation over India are observed. The insensitivity of the ISM to the elevated heating of the southern TP indicates that the "diabatic heating" may not be the major forcing for the enhancement of the ISM due to the presence of the southern TP (Fig. 4a). Other mechanisms, e.g. the "thermal insulation" effect (Boos and Kuang 2010), might be more important. As shown in Fig. 3a, without any orography, there is a northeasterly wind across the TP to northern India. This is a part of the eastern side of the subtropical anticyclone over western and central Asia. The presence of the southern TP blocks this northeasterly wind (Fig. 6b). According to Boos and Kuang (2010), this protects the high near-surface entropy air over India from the extratropical low entropy air, therefore maintains an upper-level thermal high over northern India that supports a stronger ISM.

The increased heating over the central and northern TP (Fig. 9b, c), also gives rise to a cyclonic wind anomaly around the TP, which greatly enhances the precipitation over East China, but reduces the precipitation over India (particularly the northern Bay of Bengal). The heating of
$700 \mathrm{hPa}$. The region dotted with coral colour denotes precipitation anomalies significant with a Student's $t$ test $(p<0.1)$. The black vectors indicate that either the zonal or meridional wind differences are significant with a Student's $t$ test $(p<0.1)$

the Tianshan-Altai Mountains also have similar effect (data not shown). This largely explains the changes of the ISM and EASM due to the presence of the central TP, northern TP and the Tianshan-Altai Mountains (cf. Figs. 4b, c, 9b, c). It is shown that the elevated heating of the central and northern TP is crucial for the strengthening of the EASM (Fig. 9b, c). This coincides with the studies by Duan et al. (2008) and Wu et al. (2012), but disagrees with the recent studies which imply that the heating of the plateau may have negligible influence on destabilizing the atmosphere over East Asia (Boos and Kuang 2010; Park et al. 2012).

In contrast to the thermal effect of the central and northern TP, the surface heating over the Zagros Mountains promotes the ISM (Fig. 9d). This agrees with previous studies (Wu et al. 2012; Zaitchik et al. 2007; Zarrin et al. 2011), which emphasize the importance of diabatic heating of the Zagros Mountains in lowering the sea level pressure and inducing the low-level cyclonic wind surround the mountains that may reinforce the ISM, particularly over northwestern India. However, such heating effect is relatively small compared to the full impact of the Zagros Mountains (cf. Figs. 4d, 9d). This indicates that the thermal insulation or the mechanical effect of the Zagros 
Fig. 10 Meridional vertical transect of summer circulation averaged between $80^{\circ} \mathrm{E}$ and $95^{\circ} \mathrm{E}$ and between $105^{\circ} \mathrm{E}$ and $120^{\circ} \mathrm{E}$. a, b MsTibet minus M00, c, d McTibet minus MsTibet, e, f MnTibet minus McTibet, $\mathbf{g}$, h MZagros minus MnTibet. The shaded colour denotes the difference in zonal wind speed ( $\mathrm{u}$, unit: $\mathrm{m} \mathrm{s}^{-1}$ ). The differences significant with a Student's $t$ test $(p<0.1)$ are dotted with green colour. The vector shows the difference in meridional ( $\mathrm{v}$, unit: $\mathrm{m} \mathrm{s}^{-1}$ ) and vertical $\left(-\omega\right.$, unit: $\left.50 \times \mathrm{Pa} \mathrm{s}^{-1}\right)$ wind components. The difference significant with a Student's $t$ test $(p<0.1)$ are in black colour. Grid cells with pressure larger than the surface pressure are shaded by black colour

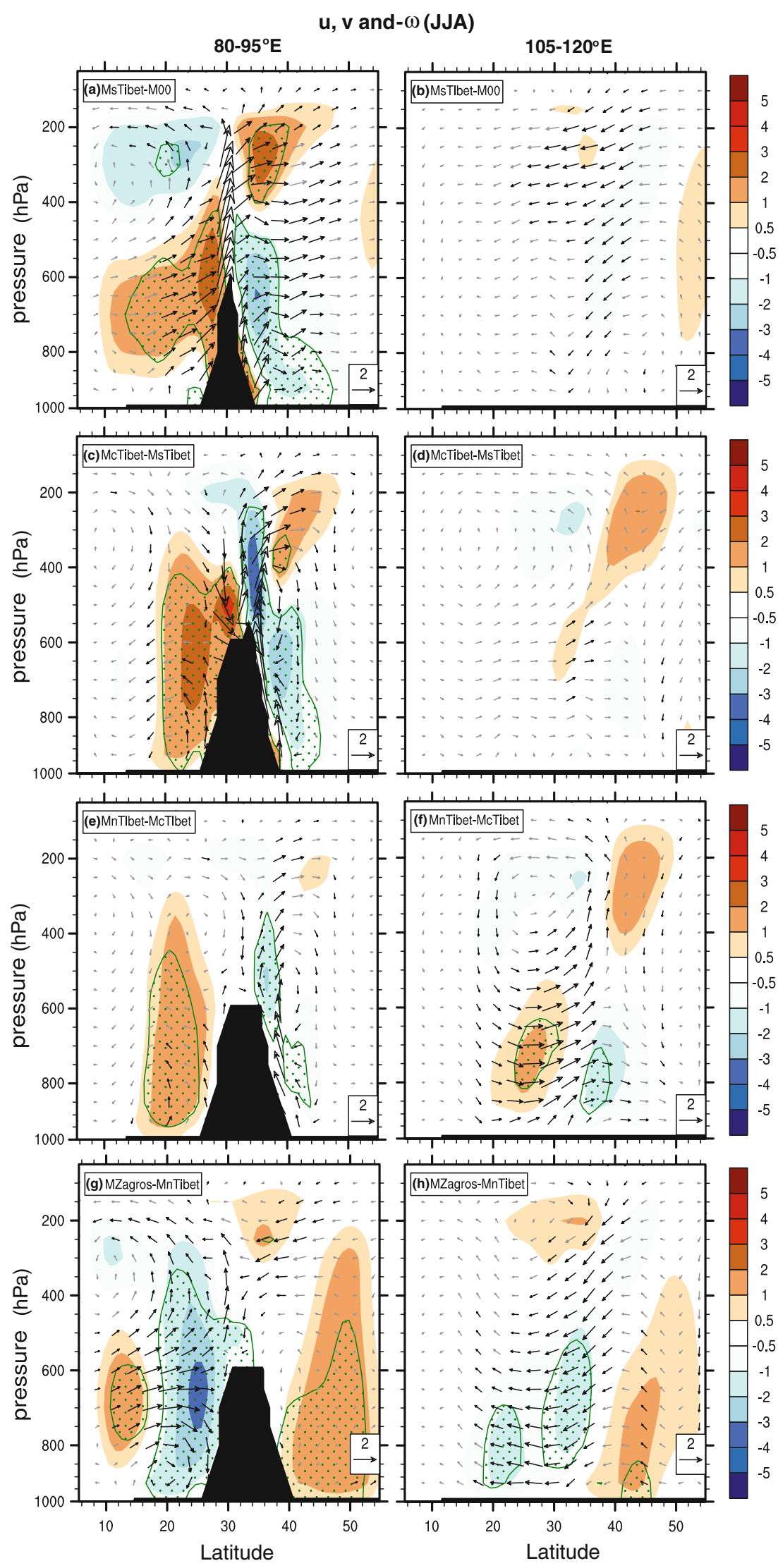


Mountains may also play a substantial role. As shown in Fig. 6d, without the Zagros Mountains, there is a strong northwesterly wind across the Zagros Mountain region to northern India. The presence of the Zagros Mountains blocks this flow (Fig. 6e). This may also act as a thermal insulator as proposed by Boos and Kuang (2010) that sustains a stronger ISM. However, compared to the effect of the southern TP which thermal insulation effect is dominant, the effect of the Zagros Mountains is different in several aspects. For instance, the upper-level thermal maximum over northern India is not as greatly enhanced by the presence of the Zagros Mountains as that by the southern TP (cf. Fig. 8c, f). There is strong westerly (northwesterly) wind anomaly to the north (east) of the TP due to the presence of the Zagros Mountains (Fig. 4d), which is not produced by the presence of the southern TP (Fig. 4a). Therefore, we argue that the mechanical blocking and deflecting of the low-level westerly flows around the TP by the Zagros Mountains might play a more prominent role in affecting the Asian summer monsoons (see more discussion in Sect. 4.2).

It is interesting to note that the thermal insulation and diabatic heating of the TP have distinct (or even opposite) effects on the Asian summer monsoons. Figure 10 illustrates the meridional vertical transects of the circulation changes over TP-India and E-China in response to regional mountain uplift. In the case of the uplift of the southern TP which thermal insulation effect is dominant, coupled easterly (westerly) wind anomalies (blue (red) shading) to the south of the plateau and westerly (easterly) wind anomalies to the north of the plateau in the upper (lower) troposphere are evident (Fig. 10a) due to the enhanced upper tropospheric thermal maximum over northern India. The ISM is primarily intensified through the stimulated traverse and meridional monsoon circulation (Fig. 7b), while the EASM is hardly affected (or even slightly reduced) (Figs. 10b, 7b).

In the case of the uplift of the central and northern TP when the diabatic heating effect is pronounced, only a lower and middle level westerly (easterly) wind anomaly to the south (north) of the TP is observed (Fig. 10c, e). The ISM is suppressed primarily by the weakened low-level monsoon vorticity (as depicted by IMI in Fig. 7). The EASM, however, is greatly promoted (Fig. 9b, c). This has been attributed to the coupled lower (upper) level southerly (northerly) wind over E-China that favors ascending motion according to vorticity balance equation (Duan et al. 2008). But this interpretation does not explain the zonal elongated feature of the precipitation increase due to the presence of the central and northern TP (Fig. 4b, c).

The zonal elongated precipitation enhancement coincides with the mean position of the subtropical rain front over East Asia, which is primarily formed by the confluence of the mid-tropospheric westerly flow from the north and south of the TP (Liang and Wang 1998; Molnar et al. 2010; Sampe and Xie 2010). It has been suggested that the horizontal warm advection brought by the westerly flow from the south of the TP plays a major role in initiating and maintaining convective activities (i.e. upward motion) along this subtropical front (Sampe and Xie 2010). In our experiments, the middle and lower level westerly flow from the south of the plateau to East Asia is strengthened by the presence of the central and northern TP (Fig. 10d, f). This brings about an enhanced warm advection over E-China (Fig. 11c, d), therefore explains the intensified precipitation along the subtropical rain front. Note that the precipitation initiated by warm advection can induce latent heat release therefore warms the upper troposphere. This may facilitate the upper tropospheric

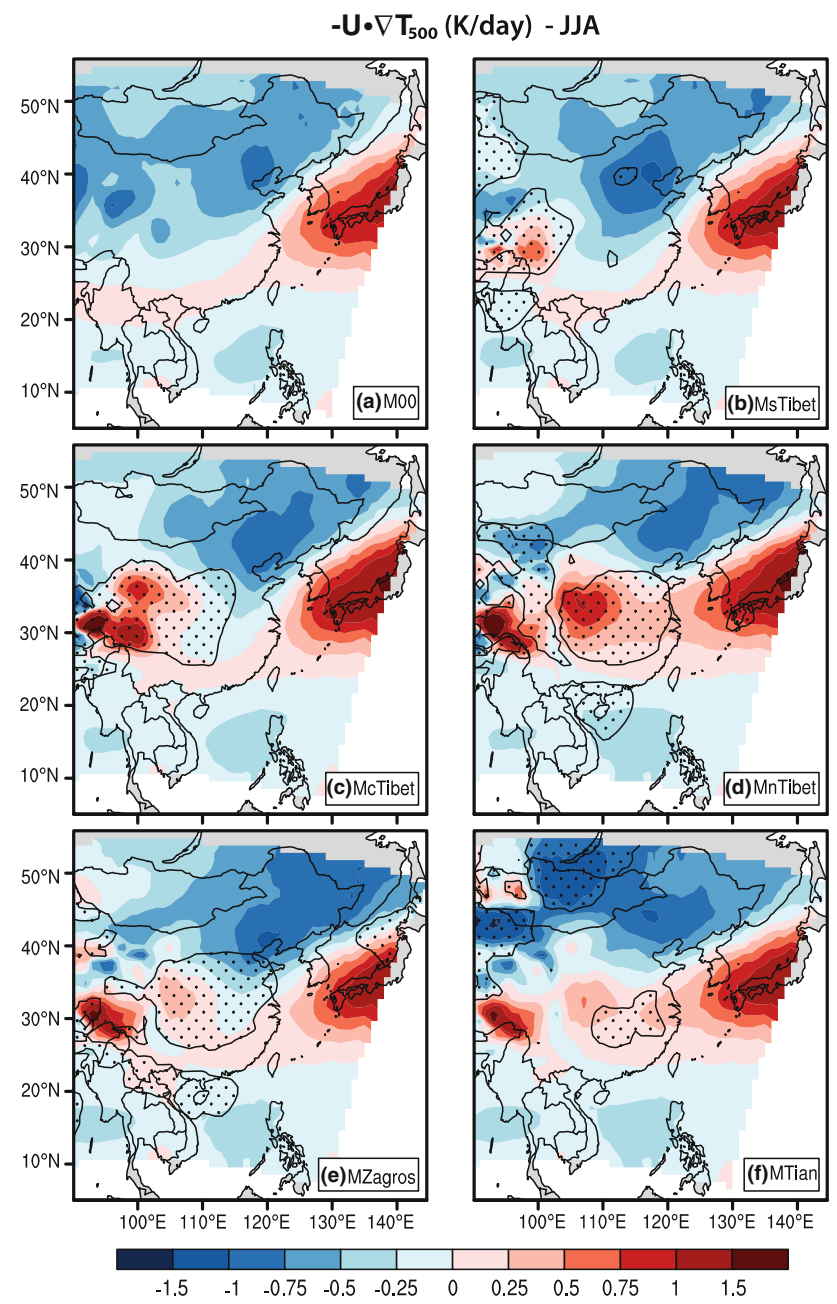

Fig. 11 Summer mean $500 \mathrm{hPa}$ horizontal advection of temperature $\left(\mathrm{K} \mathrm{day}^{-1}\right)$. a M00, b MsTibet, c McTibet, d MnTibet, e MZagros, f MTian. The black dotted region denotes the area where the difference of thermal advection from previous experiment is significant with a Student's $t$ test $(p<0.1)$ 
divergence that further draws the low-level southerly wind bringing moisture inland-ward (Sampe and Xie 2010). This positive feedback accounts for the upper tropospheric anticyclonic wind response over northern China (Fig. 8d, e) and the strengthened meridional overturning over East Asia (Fig. 10d, f) in these experiments.

\subsection{Dynamical effects}

It has been long recognized that the uplifted TP also acts as a physical barrier, which splits and deflects the mid-latitude westerly flow, excites topographic Rossby wave response and transient disturbance and hence, modifies the Asian monsoon climate (Hahn and Manabe 1975; Liu et al. 2007; Molnar et al. 2010; Park et al. 2012; Rodwell and Hoskins 2001; Trenberth and Chen 1988). However, since the midlatitude westerlies weaken and displace northward in summer, the mechanical effect of the TP on the summer monsoons is thought to be much weaker than that on the winter monsoon (Yanai and Wu 2006). As discussed in previous section, the mechanical effect seems to be trivial compared to the thermal isulation or sensible heating effect in modulating the summer monsoons when the southern, central and northern TP are present. However, the mechanical effect of the Zagros Mountains may exert substantial impact on the ISM and EASM. The blocking of the low-level westerly flow by the Zagros Mountains to the south of the TP greatly facilitates the ISM vorticity (Fig. $10 \mathrm{~g}$ ), while suppresses the westerly flow and warm advection from the south of the TP to East Asia (Figs. 10h, 11e). Such effect is just opposite to that of the diabatic heating of the central and northern TP, leading to a stronger ISM but weaker EASM.

We also notice that although the mechanical effects of the central TP on the seasonal average of the summer monsoons are negligible, they are prominent in spring and early summer (e.g. June) when both the ISM and EASM are most subjective to the position and strength of the westerly jet (Sampe and Xie 2010; Schiemann et al. 2009). The mechanical effects of the central TP are similar to its diabatic heating effect that diminishes the ISM but promotes the EASM (Figure not shown).

\subsection{Comparison with synchronous summer monsoon response}

Compared to regional mountain uplift which gives rise to an out-of-phase summer monsoon changes in India and East Asia, the bulk mountain uplift generally intensifies both the ISM and EASM (Figs. 3, 7). Likewise, in the combined effect of several mountain regions, such as McTibet minus M00, MZagros minus MsTibet, or MTian minus McTibet, a synchronous strengthening of the ISM and EASM may also be observed (Figs. 5, 7).

We propose that such synchronous summer monsoon strengthening can only be induced when the uplifted mountains have reached to the extent that its elevated surface heating effect is sufficient to enhance the EASM, while the thermal insulation (or the mechanical blocking) effect of the mountains can be adequate to intensify the ISM. This is in contrast to the asynchronous summer monsoon response, which is produced because the extent of the uplifted mountains is relatively small and only their thermal insulation effect (e.g. MsTibet - M00), or the diabatic heating (e.g. MnTibet - McTibet) is at work.

As manifested in our results (Fig. 3), the increase of Indian summer rainfall is greater in the earlier stage of bulk mountain uplift (i.e. M50 - M00). In contrast, the East Asian summer rainfall appears to be more increased by the later stage of bulk mountain uplift (i.e. M100 - M50). This is in agreement with previous modeling study by An et al. (2001). We suggest that such non-linear responses of the two monsoon systems to the height of the mountains, can be particularly related to the mechanisms governing these two monsoons. The ISM is mainly intensified by the thermal insulation of the Asian orography that essentially offers a protection of the sub-cloud high entropy air over India from the low entropy extratropical air (Boos and Kuang 2010). According to this mechanism, the earlier stage of the bulk mountain uplift could have been sufficient to protect the low-level high entropy air over India therefore greatly enhances the ISM. This speculation is supported by the sensitivity experiments showing that increasing the height of the south TP from 0 to $50 \%$ of the present-day height has much stronger impact on the ISM than that from 50 to $100 \%$ of the present-day height (see Fig. S3 in Online Resource 2). In comparison, the EASM is mainly driven by the elevated surface heating of the TP. Such heating at higher elevation has a larger effect on atmospheric circulation than at lower elevation, because the relatively small mass of the overlying air at higher elevation (compared to that at lower elevation) can have greater temperature increase (decrease) per unit heating (cooling) (Kutzbach et al. 1993). As a result, the EASM can be more intensified during the later stage of the bulk mountain uplift. Nevertheless, we note that the sensitivity of the EASM and ISM to bulk mountain height is very model-dependent. While Kutzbach et al. (1989) document a linear response of the summer monsoons to bulk mountain height, Abe et al. (2003) and Kitoh (2004) find that the enhancement of the ISM (EASM) in the later stages of the bulk mountain uplift is larger (smaller) than in the earlier stages. More studies are needed to better understand such discrepancies. 


\section{Implication for summer monsoon evolution in the Neogene}

Although our regional mountain uplift experiments are not designed to exactly simulate the climate of specific geological periods, a tentative comparison between our model results and the monsoon proxies still provides insights to the mechanisms for the Asian monsoon evolution in the past. As indicated by the mean hypsodonty (i.e. tooth height) of the large mammal herbivores, a proxy for precipitation, there was a strong drying trend of N-China from the Early Miocene (23-15 Ma) to the Middle Miocene (15-11 Ma), when India remained humid or even became slightly wetter [Fig. 12 and more details in Eronen et al. (2010)]. Such anti-phase changes of moisture conditions between N-China and India has also been revealed by other proxies (Clift et al. 2008; Liu et al. 2011). This coincides with the effect of the southern TP uplift (Fig. 4a), suggesting that the emergence of the present-day southern TP in the Middle Miocene alone (Fig. 1) may have played a major role in the monsoon development of this period. From the Middle Miocene to the early Late Miocene (11-8 Ma), India and N-China became drier synchronously, probably due to strong global cooling (Fig. 12). But in the later Late Miocene (8-5 Ma), a wetter condition in N-China is documented in the fossil records, while India was slightly drier than before (Fig. 12). Previous studies have attributed the drying of India in the later Late Miocene mainly to global cooling (Clift et al. 2008; Huang et al. 2007). This alone, however, fails to explain the strengthening of the EASM at the same time. According to our results, it is possible that the bulk mountain uplift from 50 to $100 \%$ may have counteracted global cooling effect and enhanced the EASM. But more likely, it is the substantial growth of the northern TP (or the Tianshan Mountains) during this period (Fig. 1) that was responsible for these changes. Our results also indicate a high sensitivity of the Asian summer monsoons to the presence of the Zagros and Hindu Kush Mountains. Particularly, the inception of the summer monsoon over Pakistan and northwestern India, where many terrestrial monsoon proxies were preserved (e.g. Sanyal et al. 2010), is closely associated with the growth of these mountains (Fig. 6e). The deformation of currently active fault systems over the Zagros Mountains mostly started or intensified at $\sim 5 \pm 2$ Ma (Allen et al. 2004; Axen et al. 2001; Copley and Jackson 2006). This coincided with the decline of the summer monsoon in East Asia (Ding et al. 1999; Jiang et al. 2010) and the enhancement of the Himalayan exhumation (Clift et al. 2008) and the summer monsoon wind over the Arabian Sea (Huang et al. 2007) at $\sim 4 \mathrm{Ma}$. Whether such monsoon changes were related to the rising of the Zagros Mountains requires further investigation. To

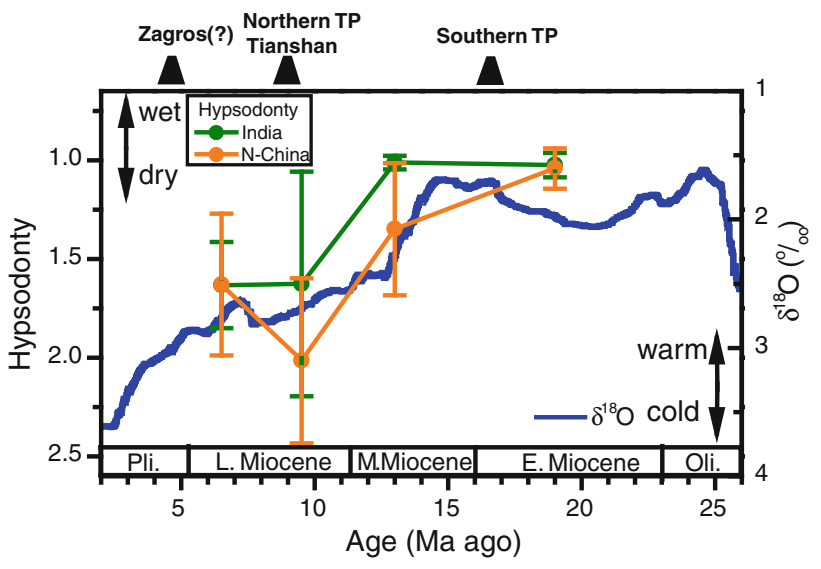

Fig. 12 The changes of mean hypsodonty of large mammal (herbivore) fossil teeth over N-China and India during the Miocene (based on Eronen et al. 2010) and its relation with global cooling (Zachos et al. 2001) and regional mountain uplift. Note that higher hypsodonty values indicate drier conditions (i.e. weaker summer monsoon), and vice versa

this end, more accurate paleoaltimetry studies over the Zagros and Hindu Kush Mountains would be particularly needed.

\section{Summary and conclusions}

In this study, a regional climate model is applied to explore the influence of diachronous mountain uplift on the Asian summer monsoon. Our results show that, unlike the bulk mountain uplift which induces a synchronous strengthening of both the Indian and East Asian summer monsoon (i.e. ISM and EASM), the regional mountain uplift leads to an asynchronous response of the ISM and EASM. The ISM (EASM) is strengthened (weakened) by the presence of the southern TP and the Zagros Mountains, while weakened (strengthened) by the presence of the central and northern TP, and the Tianshan-Altai Mountains. The mechanisms for such asynchronous summer monsoon responses are illustrated in Fig. 13. The presence of the southern TP has a strong thermal insulation effect, which strengthens the upper tropospheric thermal high pressure over India (Fig. 13a). This promotes the ISM by invigorating the traverse and Hadley monsoon circulation, but has little influence on the EASM. In contrast, the growth of the central, northern TP and the Tianshan Mountains affects the summer monsoons mainly by their surface heating effect (Fig. 13b). It induces a low-level cyclonic wind anomaly around the TP, which weakens the ISM by suppressing the lower tropospheric monsoon vorticity in India, but enhances the EASM by increasing warm and moisture advection to East Asia that stimulates the meridional overturning circulation. Finally, the presence of the Zagros 


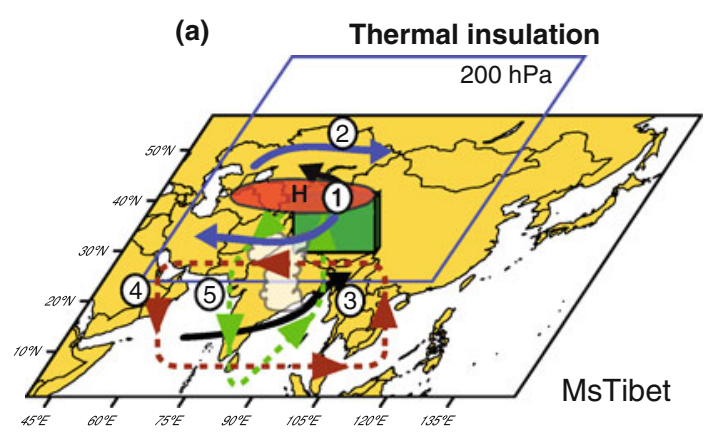

(b)

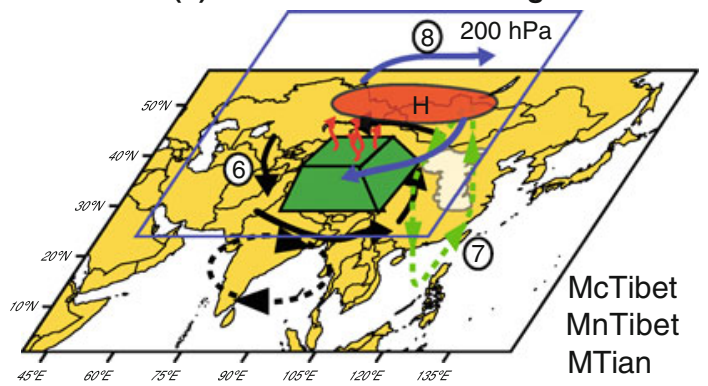

(c)

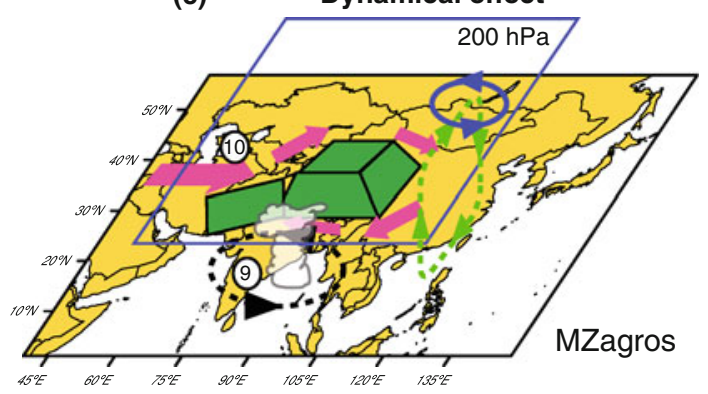

Fig. 13 Schematic diagram describing the effects of the regional mountain uplift on the ISM and EASM. a Thermal insulation, b diabatic heating, c dynamical effect. [1] upper-level thermal high pressure to the south of the TP, [2] upper-level anticyclonic wind anomaly over southern TP, [3] low-level cyclonic wind anomaly around southern TP, [4] traverse monsoon circulation (as depicted by WY), [5] meridional Hadley circulation (as depicted by MH), [6] lowlevel cyclonic wind anomaly around TP, [7] meridional overturning over East Asia, [8] upper-level anticyclonic wind anomaly over E-China, [9] low-level monsoon vorticity over India (as depicted by IMI), [10] lower and middle level westerly wind

Mountains can enhance the ISM by its sensible heating effect, but more importantly it can mechanically block the mid-latitude westerly flow to the south of the TP (Fig. 13c). This triggers a clock-wise wind anomaly around the TP that has just the opposite effect of the surface heating on the Asian summer monsoons (cf. Fig. 13b, c). We propose that the synchronous strengthening of the ISM and EASM can only be found when the elevated mountains reach to the extent that their surface heating effect is favorable for a stronger EASM, while their thermal insulation (or mechanical blocking) effect is sufficient to maintain a stronger ISM.
We note several limitations of our regional model experiments. Firstly, the regional model is unable to cover all the area that is vital for the Asian summer monsoons, such as the subtropical anticyclone over western Asia and Western North Pacific, and the tropical Indian Ocean. The one-way nesting of our regional model in the global model does not allow the interaction between the global circulation and orography. Both may affect the monsoon response to mountain uplift. Moreover, the atmospheric-ocean interaction has been shown to be of relevance in determining the effect of mountain uplift on the Asian monsoon (Kitoh 2004). Such interaction, however, is missing in our model. This may be responsible for the lack of changes over the sea with the mountain uplift in our results (Fig. 4). Finally, the scenarios of the regional mountain uplift in this study are not exhaustive. The order in which each mountain region appears may significantly affect their perceived effect on the Asian summer monsoon. For instance, if the Zagros Mountains were added before the presence of the central and northern TP, its impact on the ISM may not be as strong as that shown in our results (cf. Fig. $4 d$ and Fig. S1 in Online Resource 2). In spite of these limitations, our findings still offer useful insights to the Asian monsoon evolution and its interactions with tectonic changes in the Neogene. In this study, we focused on the influence of the regional mountain uplift on summer monsoon. Its impact on winter monsoon is beyond the scope of the paper, but is worth investigating in the future.

Acknowledgments We thank the Ella and Georg Ehrnrooth foundation for project funding. This work was also supported by the Humboldt Foundation (JTE) and the federal state Hessen (Germany) within the LOEWE initiative (AM). This is a contribution to the NECLIME framework. We acknowledge the model support of the CLM community especially from Andreas Will, Burkhardt Rockel and Hans-Jürgen Panitz. Our model experiments were performed at the Center for Scientific Computing (CSC) in Espoo (Finland) with special technical support from Juha Lento and Tommi Bergman. We would also like to thank Carl Fortelius, Liping Zhou, Anu Kaakinen, Juhani Rinne and the two anonymous reviewers for their valuable comments and fruitful discussions.

Open Access This article is distributed under the terms of the Creative Commons Attribution License which permits any use, distribution, and reproduction in any medium, provided the original author(s) and the source are credited.

\section{References}

Abe M, Kitoh A, Yasunari T (2003) An evolution of the Asian summer monsoon associated with mountain uplift-Simulation with the MRI atmosphere-ocean coupled GCM. J Meteor Soc Jpn 81(5):909-933

Allen M, Jackson J, Walker R (2004) Late Cenozoic reorganization of the Arabia-Eurasia collision and the comparison of short-term 
and long-term deformation rates. Tectonics 23(2). doi:10.1029/ $2003 \mathrm{tc} 001530$

An ZS, Kutzbach JE, Prell WL, Porter SC (2001) Evolution of Asian monsoons and phased uplift of the Himalayan Tibetan plateau since Late Miocene times. Nature 411(6833):62-66

Axen GJ, Lam PS, Grove M, Stockli DF, Hassanzadeh J (2001) Exhumation of the west-central Alborz Mountains, Iran, Caspian subsidence, and collision-related tectonics. Geology 29(6):559_ 562

Bollasina M, Nigam S (2010) The summertime "heat" low over Pakistan/northwestern India: evolution and origin. Clim Dyn 37(5-6):957-970. doi:10.1007/s00382-010-0879-y

Boos WR, Kuang ZM (2010) Dominant control of the South Asian monsoon by orographic insulation versus plateau heating. Nature 436(7278):218-223

Chakraborty A, Nanjundiah RS, Srinivasan J (2002) Role of Asian and African orography in Indian summer monsoon. Geophys Res Lett 29(20). doi:10.1029/2002g1015522

Chow KC, Liu YM, Chan JCL, Ding YH (2006) Effects of surface heating over Indochina and India landmasses on the summer monsoon over South China. Int J Climatol 26(10):1339-1359

Clift PD, Hodges KV, Heslop D, Hannigan R, Van Long H, Calves G (2008) Correlation of Himalayan exhumation rates and Asian monsoon intensity. Nat Geosci 1(12):875-880. doi:10.1038/ ngeo351

Copley A, Jackson J (2006) Active tectonics of the Turkish-Iranian Plateau. Tectonics 25(6). doi:10.1029/2005tc001906

Currie BS, Rowley DB, Tabor NJ (2005) Middle Miocene paleoaltimetry of southern Tibet: implications for the role of mantle thickening and delamination in the Himalayan orogen. Geology 33(3):181-184

Cyr AJ, Currie BS, Rowley DB (2005) Geochemical evaluation of Fenghuoshan Group lacustrine carbonates, north-central Tibet: implications for the paleoaltimetry of the eocene Tibetan Plateau. J Geol 113(5):517-533. doi:10.1086/431907

DeCelles PG, Quade J, Kapp P, Fan MJ, Dettman DL, Ding L (2007) High and dry in central Tibet during the late Oligocene. Earth Planet Sci Lett 253(3-4):389-401. doi:10.1016/j.epsl.2006. 11.001

Ding ZL, Xiong SF, Sun JM, Yang SL, Gu ZY, Liu TS (1999) Pedostratigraphy and paleomagnetism of a similar to $7.0 \mathrm{Ma}$ eolian loess-red clay sequence at Lingtai, Loess Plateau, northcentral China and the implications for paleomonsoon evolution. Palaeogeogr Palaeoclimatol Palaeoecol 152(1-2):49-66

Dobler A, Ahrens B (2010) Analysis of the Indian summer monsoon system in the regional climate model COSMO-CLM. J Geophys Res 115:D16101. doi:10.1029/2009jd013497

Dobler A, Ahrens B (2011) Four climate change scenarios for the Indian summer monsoon by the regional climate model COSMO-CLM. J Geophys Res 116, D24104. doi:10.1029/ 2011JD016329

Duan AM, Wu GX (2005) Role of the Tibetan Plateau thermal forcing in the summer climate patterns over subtropical Asia. Clim Dyn 24(7-8):793-807

Duan AM, Wu GX, Liang XY (2008) Influence of the Tibetan Plateau on the summer climate patterns over Asia in the IAP/LASG SAMIL model. Adv Atmos Sci 25(4):518-528. doi:10.1007/ s00376-008-0518-2

Eronen JT, Ataabadia MM, Micheelsb A, Karme A, Bernor RL, Fortelius M (2009) Distribution history and climatic controls of the Late Miocene Pikermian chronofauna. Proc Natl Acad Sci USA 106(29):11867-11871. doi:10.1073/pnas.0902598106

Eronen JT, Puolamäki K, Liu L, Lintulaakso K, Damuth J, Janis C, Fortelius M (2010) Precipitation and large herbivorous mammals, part II: application to fossil data. Evol Ecol Res $12: 235-248$
Fluteau F, Ramstein G, Besse J (1999) Simulating the evolution of the Asian and African monsoons during the past $30 \mathrm{Myr}$ using an atmospheric general circulation model. J Geophys Res 104(D10):11995-12018. doi:10.1029/1999JD900048

Fortelius M, Eronen J, Jernvall J, Liu LP, Pushkina D, Rinne J, Tesakov A, Vislobokova I, Zhang ZQ, Zhou LP (2002) Fossil mammals resolve regional patterns of Eurasian climate change over 20 million years. Evol Ecol Res 4(7):1005-1016

Gao XJ, Xu Y, Zhao ZC, Pal JS, Giorgi F (2006) On the role of resolution and topography in the simulation of East Asia precipitation. Theor Appl Climatol 86(1-4):173-185. doi: 10.1007/s00704-005-0214-4

Garzione CN, Dettman DL, Quade J, DeCelles PG, Butler RF (2000) High times on the Tibetan Plateau: paleoelevation of the Thakkhola graben, Nepal. Geology 28(4):339-342

Goswami BN, Krishnamurthy V, Annamalai H (1999) A broad-scale circulation index for the interannual variability of the Indian summer monsoon. Q J R Meteor Soc 125(554):611-633

Gunnell Y (1997) Relief and climate in South Asia: the influence of the Western Ghats on the current climate pattern of peninsular India. Int J Climatol 17(11):1169-1182

Guo ZT, Sun B, Zhang ZS, Peng SZ, Xiao GQ, Ge JY, Hao QZ, Qiao YS, Liang MY, Liu JF, Yin QZ, Wei JJ (2008) A major reorganization of Asian climate by the early Miocene. Clim Past 4(3): $153-174$

Hahn DG, Manabe S (1975) Role of mountains in South Asian monsoon circulation. J Atmos Sci 32(8):1515-1541

Harris N (2006) The elevation history of the Tibetan plateau and its implications for the Asian monsoon. Palaeogeogr Palaeoclimatol Palaeoecol 241(1):4-15

Huang YS, Clemens SC, Liu WG, Wang Y, Prell WL (2007) Largescale hydrological change drove the late Miocene $\mathrm{C}_{4}$ plant expansion in the Himalayan foreland and Arabian Peninsula. Geology 35(6):531-534. doi:10.1130/g23666a.1

Jiang HC, Ding ZL (2008) A 20 Ma pollen record of East-Asian summer monsoon evolution from Guyuan, Ningxia, China. Palaeogeogr Palaeoclimatol Palaeoecol 265(1-2):30-38. doi: 10.1016/j.palaeo.2008.04.016

Jiang DB, Ding ZL, Drange H, Gao YQ (2008) Sensitivity of East Asian climate to the progressive uplift and expansion of the Tibetan Plateau under the Mid-Pliocene boundary conditions. Adv Atmos Sci 25(5):709-722. doi:10.1007/s00376-008-0709-x

Jiang HC, Mao X, Xu HY, Thompson J, Ma XL (2010) 4 Ma coarsening of sediments from Baikal, Chinese Loess Plateau and South China Sea and implications for the onset of $\mathrm{NH}$ glaciation. Palaeogeogr Palaeoclimatol Palaeoecol 298(3-4):201-209

Kitoh A (2004) Effects of mountain uplift on East Asian summer climate investigated by a coupled atmosphere-ocean GCM. J Clim 17(4):783-802

Kutzbach JE, Guetter PJ, Ruddiman WF, Prell WL (1989) Sensitivity of climate to Late Cenozoic uplift in Southern Asia and the American West-numerical experiments. J Geophys Res 94(D15):18393-18407. doi:10.1029/JD094iD15p18393

Kutzbach JE, Prell WL, Ruddiman WF (1993) Sensitivity of eurasian climate to surface uplift of the Tibetan Plateau. J Geol 101(2):177-190

Li C, Yanai M (1996) The onset and interannual variability of the Asian summer monsoon in relation to land-sea thermal contrast. J Clim 9(2):358-375. doi:10.1175/1520-0442(1996)009<0358: toaivo $>2.0$. co; 2

Liang XZ, Wang WC (1998) Associations between China monsoon rainfall and tropospheric jets. Q J R Meteor Soc 124(552): 2597-2623

Liu XD, Yin ZY (2002) Sensitivity of East Asian monsoon climate to the uplift of the Tibetan Plateau. Palaeogeogr Palaeoclimatol Palaeoecol 183(3-4):223-245 
Liu YM, Hoskins BJ, Blackburn M (2007) Impact of Tibetan orography and heating on the summer flow over Asia. J Meteor Soc Jpn 85B:1-19

Liu YS, Utescher T, Zhou ZK, Sun BN (2011) The evolution of Miocene climates in North China: preliminary results of quantitative reconstructions from plant fossil records. Palaeogeogr Palaeoclimatol Palaeoecol 304(3-4):308-317

Lucas-Picher P, Christensen JH, Saeed F, Kumar P, Asharaf S, Ahrens B, Wiltshire AJ, Jacob D, Hagemann S (2011) Can regional climate models represent the Indian monsoon? J Hydrometeorol 12(5):849-868. doi:10.1175/2011jhm1327.1

Micheels A, Bruch AA, Eronen J, Fortelius M, Harzhauser M, Utescher T, Mosbrugger V (2011) Analysis of heat transport mechanisms from a Late Miocene model experiment with a fully-coupled atmosphere-ocean general circulation model. Palaeogeogr Palaeoclimatol Palaeoecol 304(3-4):337-350

Molnar P, Boos WR, Battisti DS (2010) Orographic controls on climate and paleoclimate of Asia: thermal and mechanical roles for the Tibetan Plateau. Annu Rev Earth Planet Sci 38:77-102

Park S, Hong SY (2004) The role of surface boundary forcing over south Asia in the Indian summer monsoon circulation: a regional climate model sensitivity study. Geophys Res Lett 31(12):4. doi: 10.1029/2004g1019729

Park HS, Chiang JCH, Bordoni S (2012) Mechanical impact of the Tibetan Plateau on the seasonal evolution of the South Asian monsoon. J Clim 25:2394-2406. doi:10.1175/JCLI-D-1100281.1

Prell WL, Kutzbach JE (1992) Sensitivity of the Indian monsoon to forcing parameters and implications for its evolution. Nature 360(6405):647-652

Ramstein G, Fluteau F, Besse J, Joussaume S (1997) Effect of orogeny, plate motion and land sea distribution on Eurasian climate change over the past 30 million years. Nature 386(6627):788-795

Raschendorfer M (2001) The new turbulence parameterization of LM. COSMO Newslett 1:90-98

Ritter B, Geleyn JF (1992) A comprehensive radiation scheme for numerical weather prediction models with potential applications in climate simulations. Mon Weather Rev 120(2):303-325

Rockel B, Geyer B (2008) The performance of the regional climate model CLM in different climate regions, based on the example of precipitation. Meteor Z 17(4):487-498. doi:10.1127/09412948/2008/0297

Rodwell MJ, Hoskins BJ (2001) Subtropical anticyclones and summer monsoons. J Clim 14(15):3192-3211

Rowley DB, Currie BS (2006) Palaeo-altimetry of the late Eocene to Miocene Lunpola basin, central Tibet. Nature 439(7077):677-681

Rowley DB, Pierrehumbert RT, Currie BS (2001) A new approach to stable isotope-based paleoaltimetry: implications for paleoaltimetry and paleohypsometry of the high Himalaya since the Late Miocene. Earth Planet Sci Lett 188(1-2):253-268

Sampe T, Xie SP (2010) Large-scale dynamics of the meiyu-baiu rainband: environmental forcing by the westerly Jet. J Clim 23(1):113-134. doi:10.1175/2009jcli3128.1

Sanyal P, Sarkar A, Bhattacharya SK, Kumar R, Ghosh SK, Agrawal $S$ (2010) Intensification of monsoon, microclimate and asynchronous $\mathrm{C}_{4}$ appearance: isotopic evidence from the Indian Siwalik sediments. Palaeogeogr Palaeoclimatol Palaeoecol 296(1-2):165-173

Saylor JE, Quade J, Dellman DL, DeCelles PG, Kapp PA, Ding L (2009) The Late Miocene through present paleoelevation history of southwestern Tibet. Am J Sci 309(1):1-42

Schiemann R, Lüthi D, Schär C (2009) Seasonality and interannual variability of the westerly jet in the Tibetan Plateau region. J Clim 22(11):2940-2957. doi:10.1175/2008JCLI2625.1
Schrodin R, Heise E (2002) A new multi-layer soil model. COSMO Newslett 2:149-151

Shen F, Royden LH, Burchfiel BC (2001) Large-scale crustal deformation of the Tibetan Plateau. J Geophys Res 106(B4):6793-6816

Shi XY, Wang YQ, Xu XD (2008) Effect of mesoscale topography over the Tibetan Plateau on summer precipitation in China: a regional model study. Geophys Res Lett 35(19). doi: 10.1029/2008g1034740

Song JH, Kang HS, Byun YH, Hong SY (2010) Effects of the Tibetan Plateau on the Asian summer monsoon: a numerical case study using a regional climate model. Int J Climatol 30(5):743-759. doi:10.1002/Joc. 1906

Spicer RA, Harris NBW, Widdowson M, Herman AB, Guo SX, Valdes PJ, Wolfe JA, Kelley SP (2003) Constant elevation of southern Tibet over the past 15 million years. Nature 421(6923):622-624

Tang H, Micheels A, Eronen J, Fortelius M (2011) Regional climate model experiments to investigate the Asian monsoon in the Late Miocene. Clim Past 7(3):847-868

Tapponnier P, Xu ZQ, Roger F, Meyer B, Arnaud N, Wittlinger G, Yang JS (2001) Oblique stepwise rise and growth of the Tibet plateau. Science 294(5547):1671-1677

Tiedtke M (1989) A comprehensive mass flux scheme for cumulus parameterization in large-scale models. Mon Weather Rev 117(8):1779-1800

Trenberth KE, Chen SC (1988) Planetary-waves kinematically forced by Himalayan orography. J Atmos Sci 45(20):2934-2948

Wang B, Wu RG, Lau KM (2001) Interannual variability of the Asian summer monsoon: contrasts between the Indian and the western North Pacific-east Asian monsoons. J Clim 14(20):4073-4090

Wang PX, Clemens S, Beaufort L, Braconnot P, Ganssen G, Jian ZM, Kershaw P, Sarnthein M (2005) Evolution and variability of the Asian monsoon system: state of the art and outstanding issues. Q Sci Rev 24(5-6):595-629

Wang Y, Deng T, Biasatti D (2006) Ancient diets indicate significant uplift of southern Tibet after ca. 7 Ma. Geology 34(4):309-312. doi: $10.1130 / \mathrm{g} 22254.1$

Wang B, Wu ZW, Li JP, Liu J, Chang CP, Ding YH, Wu GX (2008a) How to measure the strength of the East Asian summer monsoon. J Clim 21(17):4449-4463. doi:10.1175/2008jcli2183.1

Wang Y, Wang XM, Xu YF, Zhang CF, Li Q, Tseng ZJ, Takeuchi G, Deng $T$ (2008b) Stable isotopes in fossil mammals, fish and shells from Kunlun Pass Basin, Tibetan Plateau: paleo-climatic and paleo-elevation implications. Earth Planet Sci Lett 270(1-2):73-85. doi:10.1016/j.eps1.2008.03.006

Webster PJ, Magana VO, Palmer TN, Shukla J, Tomas RA, Yanai M, Yasunari T (1998) Monsoons: processes, predictability, and the prospects for prediction. J Geophys Res 103(7):14451-14510

Wu G, Liu Y, He B, Bao Q, Duan A, Jin F-F (2012) Thermal controls on the Asian summer monsoon. Science report 2. doi:10.1038/ srep00404

Xie SP, Xu H, Saji NH, Wang Y, Liu WT (2006) Role of narrow mountains in large-scale organization of Asian monsoon convection. J Clim 19(14):3420-3429. doi:10.1175/JCLI3777.1

Yanai M, Wu GX (2006) Effects of the Tibetan Plateau. In: Wang B (ed) The Asian monsoon. Springer, Berlin/Heidelberg, pp 514-549

Yin A (2010) Cenozoic tectonic evolution of Asia: a preliminary synthesis. Tectonophysics 488(1-4):293-325

Zachos J, Pagani M, Sloan L, Thomas E, Billups K (2001) Trends, rhythms, and aberrations in global climate $65 \mathrm{Ma}$ to present. Science 292(5517):686-693

Zaitchik BF, Evans JP, Smith RB (2007) Regional impact of an elevated heat source: the Zagros Plateau of Iran. J Clim 20(16):4133-4146. doi:10.1175/jcli4248.1 
Zarrin A, Ghaemi H, Azadi M, Mofidi A, Mirzaei E (2011) The effect of the Zagros mountains on the formation and maintenance of the Iran anticyclone using RegCM4. Meteor Atmos Phys 112(3-4):91-100
Zhang ZS, Wang HJ, Guo ZT, Jiang DB (2007) What triggers the transition of palaeoenvironmental patterns in China, the Tibetan Plateau uplift or the paratethys Sea retreat? Palaeogeogr Palaeoclimatol Palaeoecol 245(3-4):317-331. doi:10.1016/j.palaeo.2006.08.003 